\title{
Epidemiology and Natural History of Urinary Incontinence
}

\author{
S. Hunskaar ${ }^{1}$, E. P. Arnold ${ }^{2}$, K. Burgio ${ }^{3}$, A. C. Diokno ${ }^{4}$, A. R. Herzog ${ }^{5}$ and V. T. Mallett ${ }^{6}$ \\ ${ }^{1}$ Section for General Practice, Department of Public Health and Primary Health Care, University of Bergen, Bergen, Norway; \\ ${ }^{2}$ Department of Urology, Christchurch Hospital, Christchurch, New Zealand; ${ }^{3}$ Department of Medicine, University of Alabama, \\ Birmingham, Alabama, USA; ${ }^{4}$ Department of Urology, William Beaumont Hospital, Royal Oak, Michigan, USA; ${ }^{5}$ Institute for \\ Social Research, University of Michigan, Ann Arbor, Michigan, USA; ${ }^{6}$ Division of Gynaecology, Hutzel Hospital, Detroit, \\ Michigan, USA
}

\begin{abstract}
This paper examines or current state of knowledge of the epidemiology of urinary incontinence. The population studied was community-dwelling noninstitutionalized persons. The review includes discussion of the prevalence, incidence, natural history and presence of racial and ethnic differences in the epidemiology of urinary incontinence. We also review correlates and potential risk factors that have been revealed in epidemiological studies. Differences between epidemiological and clinical approaches to a health problem, help-seeking behavior and methodological issues for research are also discussed. We have reviewed a large number of completed studies in the field of urinary incontinence, and have emphasized highquality and population-based studies. We also wished to present studies from a variety of countries. Because of the abundance of studies, only a small fraction can be presented here. Other studies may have equal standards and useful information, but lack of space precludes their inclusion.
\end{abstract}

Keywords: Children; Epidemiology; Men; Review; Urinary incontinence; Women

\section{Introduction}

In this review we emphasize the importance of understanding epidemiology, and also give a summary of the

Correspondence and offprint requests to: Professor Steinar Hunskaar, Section for General Practice, Department of Public Health and Primary Health Care, University of Bergen, Ulriksdal 8c, N-5009 Bergen, Norway. basic concepts. Epidemiology is the scientific study of the distribution and determinants of disease in people. Descriptive epidemiology is the description of disease incidence, prevalence (and mortality) by persons, place and time, whereas the term analytical epidemiology describes the search for determinants of disease risk. The discovery of risk factors and protective factors may then lead to primary or secondary prevention.

Studies of disease frequency should rely on a very specific definition of the condition under investigation. The absence of a unifying definition for urinary incontinence (UI) is a fundamental problem which has not been resolved. The lack of such a definition leads to problems with assessing the sensitivity and specificity of the findings in epidemiological studies. Variations in the availability and efficacy of health care around the world may influence the prevalence of UI.

Urinary incontinence has been defined in several ways, and this is one problem when analyzing the epidemiological studies. However, in order to obtain replicable results and to be able to compare different studies, widely accepted definitions are important. The International Continence Society (ICS) defines incontinence as 'a condition where involuntary loss of urine is a social or hygienic problem and is objectively demonstrable' [1], but this definition may not be ideal for epidemiological purposes (see below). More common in epidemiological studies are definitions based on the frequency of urine loss, e.g. 'any uncontrolled urine loss in the prior year' or 'more than two episodes in a month'. Such definitions imply that the studies are in fact studies of period prevalence.

Prevalence is defined as the probability of being incontinent within a defined population and at a defined 
time point. The concept is important for establishing the distribution of the condition in the population and for projecting the need for health and medical services. The prevalence of all-cause UI is estimated as the ratio of the number of incontinent respondents identified in a crosssectional survey to the number of all respondents in the survey (i.e. continent and incontinent). Prevalences of specific types and severity levels are estimated in an analogous manner.

Incidence is defined as the probability of developing the condition under study during a defined time period. Incidence is usually reported for 1-, 2- or 5-year time intervals.

Epidemiological surveys often must take a pragmatic approach, and therefore define incontinence type based on the symptoms alone. The classification can be done either by the researchers based on several questions, or by the respondent's confirmation of a statement or typical description. Clinical assessment allows for more differentiation of subtypes. Possible biases will be discussed below.

Severity of incontinence is another important factor for the prevalence estimate. Severity can be defined by factors such as frequency, amount and subjective nuisance. Examples of how the prevalence differs when based on different definitioins for severity will be shown.

\section{Epidemiology of Enuresis and UI in Children}

Primary enuresis is bedwetting occurring without a dry continence break of more than 6 months. Secondary enuresis refers to that returning after a longer interval of dryness. Secondary enuresis may signify behavioral, neurological, infective causes, or chronic retention with overflow, and these require careful consideration. The two clinical types are pure monosymptomatic primary noctural enuresis (MPNE) and those where the nocturnal bedwetting is associated with diurnal urgency and urge incontinence; this is referred to as polysymptomatic primary enuresis (PPE), which is less common.

Most epidemiological studies link primary and secondary enuresis together and also include monosymptomatic and polysymptomatic cases. In reviewing the literature on enuresis, it is clear that there is a wide range of prevalence in different studies, partly owing to the inclusion criteria. For some authors enuresis is defined as wetting once a month or once in 3 months, whereas for others it is more than once a week, and in many papers there is no frequency defined at all.

The best studies are longitudinal cohort studies, but many are cross-sectional and some are case controlled and look simply at the patients referred to a clinic, and then to estimate the size of the at-risk population. In some cultures parents are more complacent about bedwetting than in others and do not regard it as a problem requiring attention. These problems in under- standing epidemiology were summarized succinctly by Krantz et al. [2], who also reviewed the published epidemiological studies.

To address the difficulties in defining enuresis, in 1989 it was proposed that noctural enuresis should be classified according to simultaneous overnight EEG and cystometry studies [3]. There are, however, no large population-based studies on enuresis based on such diagnostic evaluation.

\section{Longitudinal Cohort Studies}

A child development study has followed 1139 children born in one year in Dunedin, New Zealand, and obtained an impressive $92 \%$ follow-up 9 years later [4,5]. It was found that primary enuresis usually remits with age (Fig. 1). Another cohort born in 1977 in Christchurch, New Zealand, was followed up annually. It was found that by the age of $8,7 \%$ had nocturnal enuresis, although this included some who had relapsed after initially becoming dry [6].

\section{Survey Studies}

In a Swedish study surveying 35567 -year-olds, $7 \%$ of girls were enuretic, $3 \%$ of whom had monosymptomatic nocturnal enuresis, and $12 \%$ of the boys had bedwetting, $7 \%$ with monosymptomatic nocturnal enuresis [7]. In a study from the United Kingdom 1176 children entering secondary school in Bristol (aged 11-12 years) showed a prevalence of $6 \%$ of 511 boys and $4 \%$ of 665 girls. The definitions were based on more than one enuretic episode in 3 months [8]. In Sydney, Australia, 2292 children aged between 5 and 12 years of age were identified using a sampling of parents voting in a compulsory election. Of those approached, $74 \%$ agreed to participate; $19 \%$ of the children had an enuretic episode once a month or

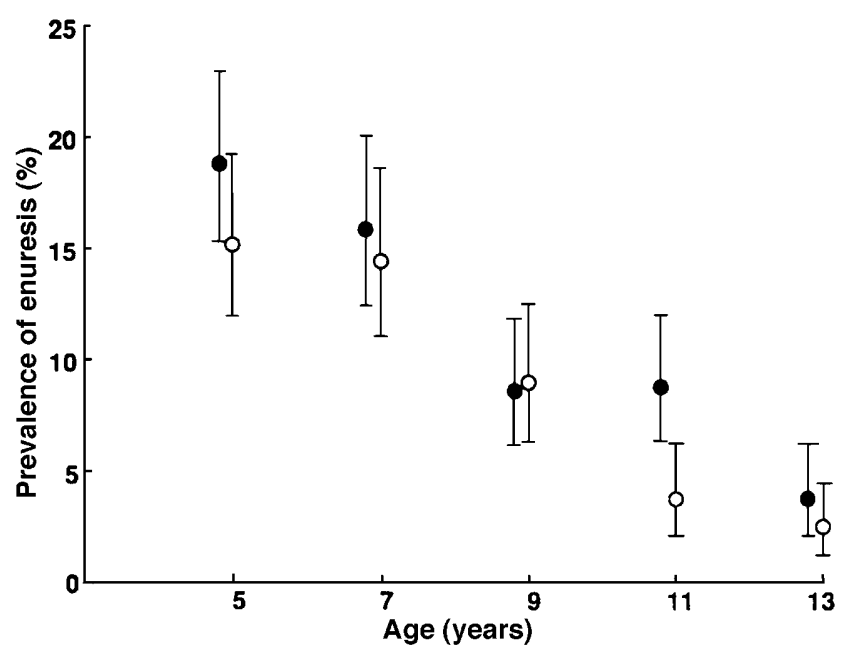

Fig. 1. Prevalence of enuresis, primary and secondary combined, for boys $(\bigcirc)$ and girls $(\bigcirc)$ separately. Ranges indicate $95 \%$ confidence intervals. (Reproduced from [5], with permission.) 
Table 1. Bedwetting from the child's and parent's points of view. Data from [11]

\begin{tabular}{lll}
\hline & $\begin{array}{l}\text { Child's view } \\
\text { (Group 1) (\%) }\end{array}$ & $\begin{array}{l}\text { Parent's view } \\
\text { (Group 2) (\%) }\end{array}$ \\
\hline Age 4-5 & 17 & 29 \\
Age 6-7 & 5 & 7 \\
\hline
\end{tabular}

more often [9]. In a Japanese study at the age of 7, 5\% of girls and $15 \%$ of boys were found to have MPNE [10]. A study from France [11] looked at prevalence from the child's point of view, interviewing 1677 children going to a school camp (group 1). The view of parents of children attending school and representing 386 children were described in group 2. Understandably, more parents than children were prepared to acknowledge the problem of bedwetting (Table 1).

\section{Potential Risk Factors}

Several risk factors have been investigated in epidemiological studies. Here we review and comment on some that are often discussed in the literature (Table 2).

Most studies have documented a strong family history, with the risk being estimated at 5-7 times higher for the child one of whose parents had been enuretic [12]. When two first-order relatives had a history of nocturnal enuresis there was a mean delay of 1.5 years in developing nocturnal bladder control. Of those with a family history of nocturnal enuresis, $91 \%$ responded to antidiuretic hormone, ADH (arginine vasopressin), compared to $7 \%$ of those without a family history [13]. A genetic study by Rittig [14] and Eiberg [15] identified an autosomal mode of inheritance with high penetrance (greater than 90\%) and suggested that a gene for persistent enuresis might be located on chromosome $13 \mathrm{q}$.

Behavioral disturbances have long been thought to be associated with enuresis. Children with secondary enuresis may be more inclined to have associated mental health disorders later in adolescence, and this group might benefit from thorough assessment of any underlying emotional disturbance or psychopathology $[16,17]$. There was, however, a lack of association between persistent primary enuresis and psychopathology in later childhood and adolescence in the study by Feehan et al. [5]. The age of achieving nocturnal control

Table 2. Risk factors for enuresis and UI in children reviewed in this text

Family history

Behavioral disturbances

Nocturnal polyuria

Depth of sleep

Sleep apnea

Urinary tract infections

Spina bifida occulta

Other neurologic conditions was also unrelated to a broad range of psychological factors, including family, social and economic background, family life event measures, changes in parents in the family and residential changes, in the study by Fergusson et al. [6].

Normal children have a diurnal rhythm of plasma arginine vasopressin (AVP), with increased levels at night, and this accounts for lower urine volume at higher osmolality. Some enuretics have less pronounced increases of AVP at night [18], and hence produce nocturnal polyuria. It has been shown that nonresponders to desmopressin (DDAVP), which is an analog of $\mathrm{ADH}$ and normal controls have normal nocturnal urine volumes, in contrast to the polyuria shown in the responders to DDAVP. This implies that the nocturnal urine production exceeds the enuresis reflex threshold of the bladder in some children, but there may also be others in whom the enuresis is not so dependent on the bladder volume.

Despite clinical impressions, objective studies using cystometry and EEG have failed to correlate the depth of sleep with arousal stages in patients with nocturnal enuresis at the time of wetting [19]. From a study of adolescent and adult patients with nocturnal enuresis enuretic episodes were observed in every sleep stage, suggesting that nocturnal enuresis may not be associated specifically with impaired awakening from deep sleep [20].

Sleep apnea has been associated with enuresis in some patients. This has been explained as the apnea inducing an increase in atrial natriuretic factor, which in turn reduces renin production and hence aldosterone levels, causing a diuresis and hence an enuretic episode due to an excess of volume. Treatment of the apnea reverses all of the above [21].

Urinary tract infections appear to have a very infrequent association with primary monosymptomatic nocturnal enuresis. However, children with secondary nocturnal enuresis showed a significant bacteriuria in $29 \%$ of cases, and the enuresis resolved after appropriate antibiotic therapy [22].

Spina bifida occulta is a common anomaly of spinal development. It was initially thought that this might have some bearing as a neurological cause for enuresis. However, the outcome for those with enuresis appears the same whether or not a spina bifida occulta is present [23].

Overactive bladder dysfunction is common in children with myelomeningocele, and this can lead to UI that persists from birth. Patients with the tethered cord syndrome tend to develop secondary enuresis following a period of being dry, with onset as the child starts to elongate at around the age of $6-8$, so that the investigation of secondary enuresis needs to focus on excluding a neurological cause. The term Hinman bladder has been coined to describe the patient who has sphincter-active voiding, overactive bladder dysfunction and often reflux, together with UI, but in whom no detectable neurological cause can be found. 


\section{Remission and Natural History}

Most children who are enuretic eventually obtain normal control. In the study by Forsythe and Redmond [24] the spontaneous cure rate was $14 \%$ annually between the ages of 5 and $9,16 \%$ between 10 and 14 , and $16 \%$ in the 15-19-year-old age group. There remained 33 patients who were bedwetting at the age of more than 20 years $(3 \%)$. Similar rates of prevalence relating to age were noted by Feehan et al. [5]. Swithinbank et al. [25] investigated their original cohort of 1176 school children again at 15-16 years: day wetting was reported by $13 \%$ of children aged 11-12 and by 3\% of children aged $15-$ 16 . Nocturnal enuresis was reported by $5 \%$ of children at $11-12$ years and by $1 \%$ at $15-16$ years.

In a group of adults over the age of 20 with a history of enuresis which persisted at least to the age 11, nocturia began when bedwetting stopped in 41 of the 88 cases [26]. There is some evidence that people who have had a past history of enuresis have a greater chance of bladder dysfunction developing in adult life. In a random cross-section of 2613 women aged 30-59 years of age, $17 \%$ reported incontinence. Childhood bedwetting was associated with a prevalence of urge incontinence, with odds ratios between 1.8 and 2.2 depending on the age dry $(P<0.01)$ [27]. In another retrospective study of 1000 urodynamic records of 500 men and 500 women, $10 \%$ of the men had detrusor instability, $63 \%$ of whom had a past history of enuresis, and $29 \%$ of the women had detrusor instability, of whom $38 \%$ had a past history of enuresis beyond the age of 6 . In this group there were 140 patients: 38 of the 50 men had detrusor instability (76\%) and 55 of the 90 women $(66 \%)$ had unstable bladders [28]. The authors concluded that the link between childhood bedwetting and adult detrusor instability appeared stronger for men than for women.

\section{Epidemiology of UI in Women}

\section{Prevalence}

A large number of epidemiological studies of UI in women have been published. Some cover a wide age span, whereas others are surveys of a single age cohort or specific groups such as pregnant women. Several reviews are available [29-34]. Table 3 shows examples of the prevalence of at least some degree of UI as found in some studies.

For the elderly population a 1988 review of several European and American epidemiologic studies identified a $10 \%-40 \%$ range of prevalence estimates of the experience of any UI among older women, and suggested a preliminary prevalence of $40 \%$ as not improbable [33]. Whereas the wide range of prevalence estimates had been noted before [34], the paper systematically reviewed the evidence and suggests that the variability cannot be attributed solely to variations in the definition of UI or in study samples, as is usually
Table 3. Examples of prevalence in studies of at least some degree of UI

\begin{tabular}{lrll}
\hline Author & Reference & $\begin{array}{l}\text { Year of } \\
\text { publication }\end{array}$ & $\%$ Prevalence \\
\hline Thomas & {$[41]$} & 1980 & 10 \\
Yarnell & {$[42]$} & 1981 & 45 \\
Campbell & {$[59]$} & 1985 & 12 \\
Diokno & {$[57]$} & 1986 & 38 \\
Jolleys & {$[43]$} & 1988 & 41 \\
Molander & {$[135]$} & 1990 & 17 \\
Burgio & {$[60]$} & 1991 & 58 \\
Rekers & {$[44]$} & 1992 & 27 \\
Sandvik & {$[63]$} & 1993 & 29 \\
Brocklehurst & {$[37]$} & 1993 & 14 \\
Holtedahl & {$[137]$} & 1998 & 47 \\
Wolin & {$[35]$} & 1969 & 51 \\
Nemir & {$[36]$} & 1954 & 52 \\
\hline
\end{tabular}

done, but that differential underreporting attributable to variations in survey procedures might hold at least part of the answer. In two studies of younger nulliparous women aged under 25, the prevalence of some degree of UI was about $50 \%$ but was a clinical problem in only $5 \%$ and $6 \%$, respectively $[35,36]$.

Table 4. Examples of prevalence of UI and across the age spectrum

\begin{tabular}{|c|c|c|c|}
\hline $\begin{array}{l}\text { Author } \\
\text { (Reference) }\end{array}$ & $\begin{array}{l}\text { Year of } \\
\text { publication }\end{array}$ & $\begin{array}{l}\text { Distribution } \\
\text { by age }\end{array}$ & $\%$ Prevalence \\
\hline \multirow[t]{3}{*}{ Thomas [41] } & \multirow[t]{3}{*}{1980} & $35-64$ & 18 \\
\hline & & $65-74$ & 15 \\
\hline & & $75+$ & 16 \\
\hline \multirow[t]{4}{*}{ Yarnell [42] } & \multirow[t]{4}{*}{1981} & $17-34$ & 27 \\
\hline & & $35-64$ & 49 \\
\hline & & $65-74$ & 43 \\
\hline & & $75+$ & 59 \\
\hline \multirow[t]{7}{*}{ Holst [48] } & \multirow[t]{7}{*}{1988} & $18-24$ & 3 \\
\hline & & $25-34$ & 29 \\
\hline & & $35-44$ & 29 \\
\hline & & $45-54$ & 25 \\
\hline & & $55-64$ & 18 \\
\hline & & $65-74$ & 25 \\
\hline & & $75+$ & 14 \\
\hline \multirow[t]{4}{*}{ Mäkinen [61] } & \multirow[t]{4}{*}{1992} & 25 & 4 \\
\hline & & 35 & 15 \\
\hline & & 40 & 20 \\
\hline & & $45-55$ & 26 \\
\hline \multirow[t]{4}{*}{ Rekers [44] } & \multirow[t]{4}{*}{1992} & $35-59$ & 31 \\
\hline & & $60-64$ & 24 \\
\hline & & $65-69$ & 14 \\
\hline & & $75-79$ & 26 \\
\hline \multirow[t]{2}{*}{ Brocklehurst [37] } & \multirow[t]{2}{*}{1993} & $30-59$ & 6 \\
\hline & & $60+$ & 9 \\
\hline \multirow[t]{7}{*}{ Sandvik [63] } & \multirow[t]{7}{*}{1993} & $20-29$ & 20 \\
\hline & & $30-39$ & 25 \\
\hline & & $40-49$ & 33 \\
\hline & & $50-59$ & 38 \\
\hline & & $60-69$ & 30 \\
\hline & & $70-79$ & 31 \\
\hline & & $80+$ & 34 \\
\hline \multirow[t]{5}{*}{ Holtedahl [137] } & \multirow[t]{5}{*}{1998} & $50-54$ & 43 \\
\hline & & $55-59$ & 55 \\
\hline & & $60-64$ & 45 \\
\hline & & $65-69$ & 39 \\
\hline & & $70-74$ & 56 \\
\hline
\end{tabular}




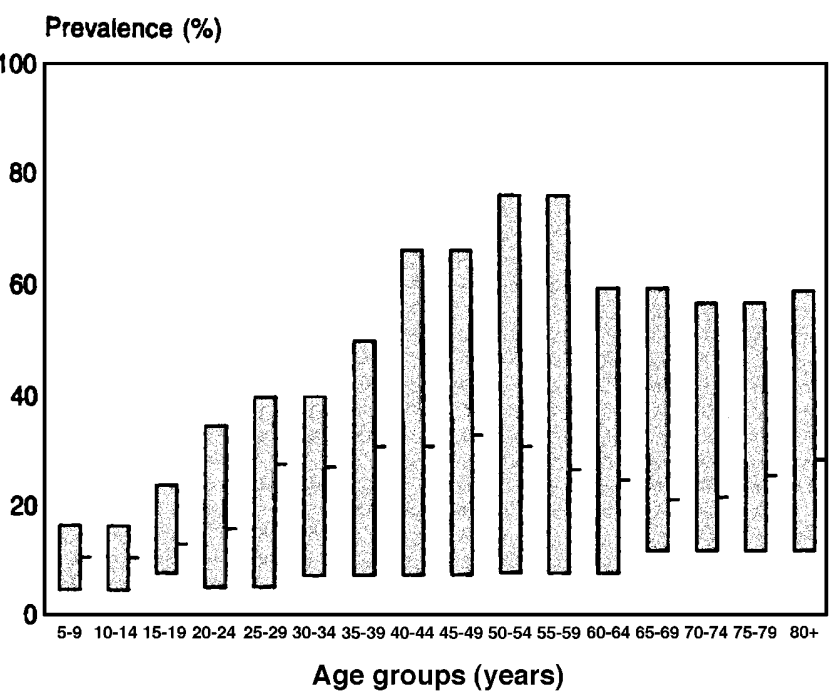

Fig. 2. Prevalence of female UI as reported in 13 different studies of the general population. Interstudy ranges are depicted by the bars, medians by the horizontal ticks. (From [152], with permission from $\mathrm{H}$. Sandvik.)

The prevalence peak (the age group with the highest prevalence of UI) also varies considerably between studies. Basically, the studies fall into two categories: those reporting the highest prevalence in old age [37-40] and those reporting the highest prevalence around the menopause [41-48]. 'High-prevalence' studies, using a lower threshold for identifying the women as incontinent, tend to show a prevalence peak in midlife, but this tendency is not consistent (Table 4).

Figure 2 shows the prevalences (interstudy ranges and medians) found in 13 studies of female UI in the general population. Only studies that cover an age span of at least 30 years are included [37-49]. We conclude that the median level of prevalence estimates gives a picture of increasing prevalence during young adult life (prevalence $20 \%-30 \%$ ), a broad peak around middle age (prevalence $30 \%-40 \%$ ), and then a steady increase in the elderly (prevalence $30 \%-50 \%$ ).

\section{Type of UI}

In surveys based on questionnaires or interviews only symptoms can be registered. Diagnoses such as motor urge incontinence or genuine stress incontinence require the use of urodynamic equipment. Several authors have reported the relative proportions of stress, urge and mixed symptoms. In Table 5 the distribution of UI types are shown, as they are found in some surveys.

Approximately $50 \%$ of all incontinent women are classified as stress incontinent, although this percentage is lower among older women. The prevalence of urge incontinence seems to increase with advancing age, and motor urge incontinence (detrusor instability) is often claimed to be the most common type of UI in the elderly [50-53]. However, these claims are based upon studies
Table 5. Relative proportions of different types of UI in the general population. Diagnoses other than stress, urge and mixed are excluded

\begin{tabular}{llrlll}
\hline Author (Ref) & $\begin{array}{l}\text { Age } \\
\text { (years) }\end{array}$ & $n$ & $\begin{array}{l}\text { Stress } \\
(\%)\end{array}$ & $\begin{array}{l}\text { Urge } \\
(\%)\end{array}$ & $\begin{array}{l}\text { Mixed } \\
(\%)\end{array}$ \\
\hline Iosif [153] & 61 & 902 & 40 & 27 & 33 \\
Hørding [88] & 45 & 515 & 75 & 11 & 14 \\
Elving [45] & $30-59$ & 2631 & 48 & 7 & 45 \\
Sommer [62] & $20-79$ & 414 & 38 & 33 & 29 \\
Harrison [47] & $20+$ & 314 & 48 & 9 & 44 \\
Yarnell [42] & $18+$ & 1000 & 50 & 19 & 31 \\
Diokno [57] & $60+$ & 1955 & 29 & 10 & 61 \\
Holst [48] & $18+$ & 851 & 52 & 25 & 23 \\
Burgio [60] & $42-50$ & 541 & 50 & 12 & 38 \\
Lara [39] & $18+$ & 556 & 48 & 27 & 21 \\
Sandvik [58] & $20+$ & 1820 & 51 & 10 & 39 \\
Mean (range) & & & $48(29-75)$ & $17(7-33)$ & $34(14-61)$
\end{tabular}

in selected groups and probably do not reflect the epidemiology of the general population [54-55]. When Diokno et al. [56] attempted to validate their population survey by urodynamic evaluation of a subsample, they found detrusor instability in only $12 \%$ of the incontinent women. One review [33] suggested that older women suffer primarily from stress or mixed urge incontinence. Diokno [57] found $56 \%$ mixed and $27 \%$ stress UI in incontinent women over 60 years of age. Hampel et al. [30] suggested a higher proportion of women with stress UI compared to mixed and urge UI, but their review included women of all ages, and the incidence of mixed UI increases with age.

Unfortunately, few studies have carefully assessed the different types and even fewer have examined their correlates. Therefore, proportions of stress and mixed types among older women are difficult to estimate, estimates vary considerably, and little is known about the risk factors and demographic correlates of the different types. But there are intriguing differences in the correlates between the different types, suggesting that the types may reflect quite different pathologies and that differentiating the types in future research might be fruitful.

Sandvik and coauthors [58] validated diagnostic questions used in a survey against a final diagnosis made by a gynecologist after urodynamic evaluation. After using the validity (sensitivity and specificity) as the basis for correcting the type distribution, the percentage of stress incontinence increased from $51 \%$ to $77 \%$, mixed incontinence was reduced from $39 \%$ to $11 \%$, and urge incontinence increased from $10 \%$ to $12 \%$. The authors concluded that mixed incontinence may be overreported in epidemiological surveys, and that correction for validity indicates that a larger majority than hitherto reported may have pure stress incontinence.

\section{Severity of UI}

Variability in the reported prevalence diminishes when only subjects with severe or 'significant' UI are examined. Most studies have operationalized the 
measurement of severe incontinence by measuring the frequency of urine loss or by asking about dampening of clothes, extra laundry, restrictions in activity or the use of protective pads. The first approach may be considered a simple attempt to operationalize the quantity of urine lost, but in none of the studies has the severity measure been validated. The second approach also reflects perceptional differences, personal hygiene and coping ability. Those reporting weekly loss or more are generally assigned to the severe category. The consistency of this measure suggests that regular incontinence is less deniable and better understood by participants. Thus it may be a more reliable figure than 'any incontinence'.

Even though the definition of severe or 'significant' incontinence varies between authors (depending on the frequency and amount of leakage, soaking of clothes, use of pads, etc.), its prevalence is considerably more consistent across different studies. Prevalence estimates range between $3 \%$ and $17 \%$, with most studies reporting between $4 \%$ and $8 \%$ [42,48,59-61]. Two studies found that the prevalence of significant incontinence tended to increase with advancing age $[42,62]$, but another found the opposite tendency [44].

It can be shown that the prevalence is dependent on 'thresholds' for diagnosis or severity (Fig. 3). For example, Sandvik et al. [63] found that nearly half of cases were classified as having slight incontinence, and only $27 \%$ as severe. Typically, slight incontinence denoted leakage of drops a few times a month, moderate incontinence daily leakage of drops, and severe incontinence larger amounts at least once a week. The authors also investigated the nuisance factor, and found that different levels of nuisance significantly affected the prevalence estimates (Fig. 4). Taken together, if only those with moderate or severe incontinence are considered, and including only those who are troubled by their leakage, the findings from that study indicate that approximately $20 \%$ of incontinent women (e.g. $6 \%$ of all adult women) may be potential patients (Fig. 5). This example emphasizes that one should be very careful with calculating numbers of patients in need of therapy based on epidemiological data.

In the elderly a review [33] noted that the prevalence estimate for severe UI (typically defined as urine loss at least weekly, 'regularly', or 'most of the time') is lower than the prevalence of any incontinence, and that the available estimates are less variable, ranging from $5 \%$ to $15 \%$ and centering around $7 \%$ (Table 6).

In summary, it is quite clear that the prevalence estimates depend significantly on the definition of severity used. It is not well established what level of severity should be regarded as clinically significant.

Table 6. The prevalence of any and severe UI among older persons investigated in the same study (Data from [33] with permission)

\begin{tabular}{llc}
\hline Author (Ref) & Any UI (\%) & Severe UI (\%) \\
\hline Campbell [59] & 12 & 3 \\
Vetter [138] & 14 & 5 \\
Yarnell [64] & 16 & 11 \\
Thomas [41] & 23 & 10 \\
Herzog [33] & 30 & 4 \\
Milne [154] & 34 & 5 \\
\hline
\end{tabular}

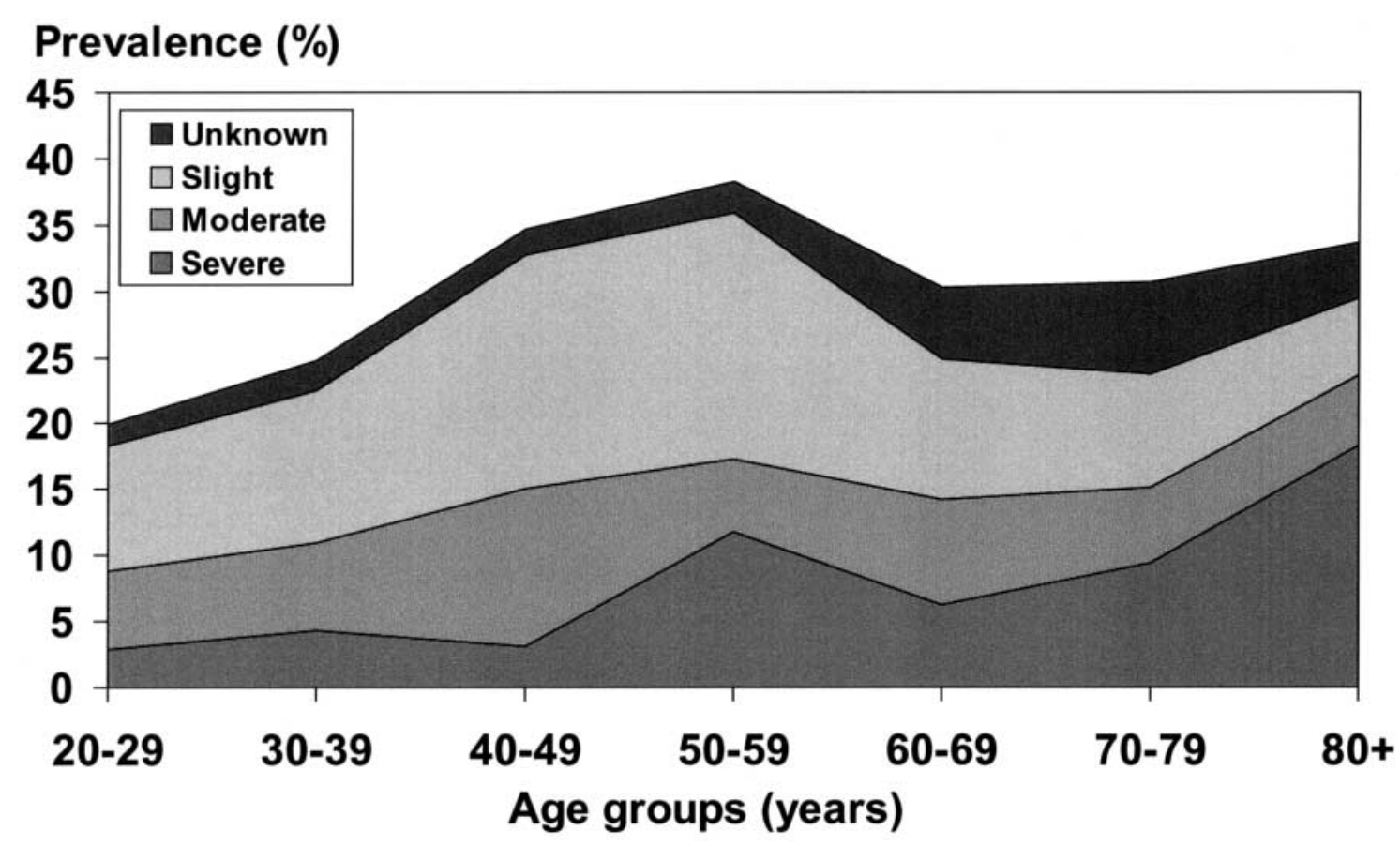

Fig. 3. Prevalence of UI when different thresholds for severity are considered. (Data from [63], with permission from H. Sandvik.) 


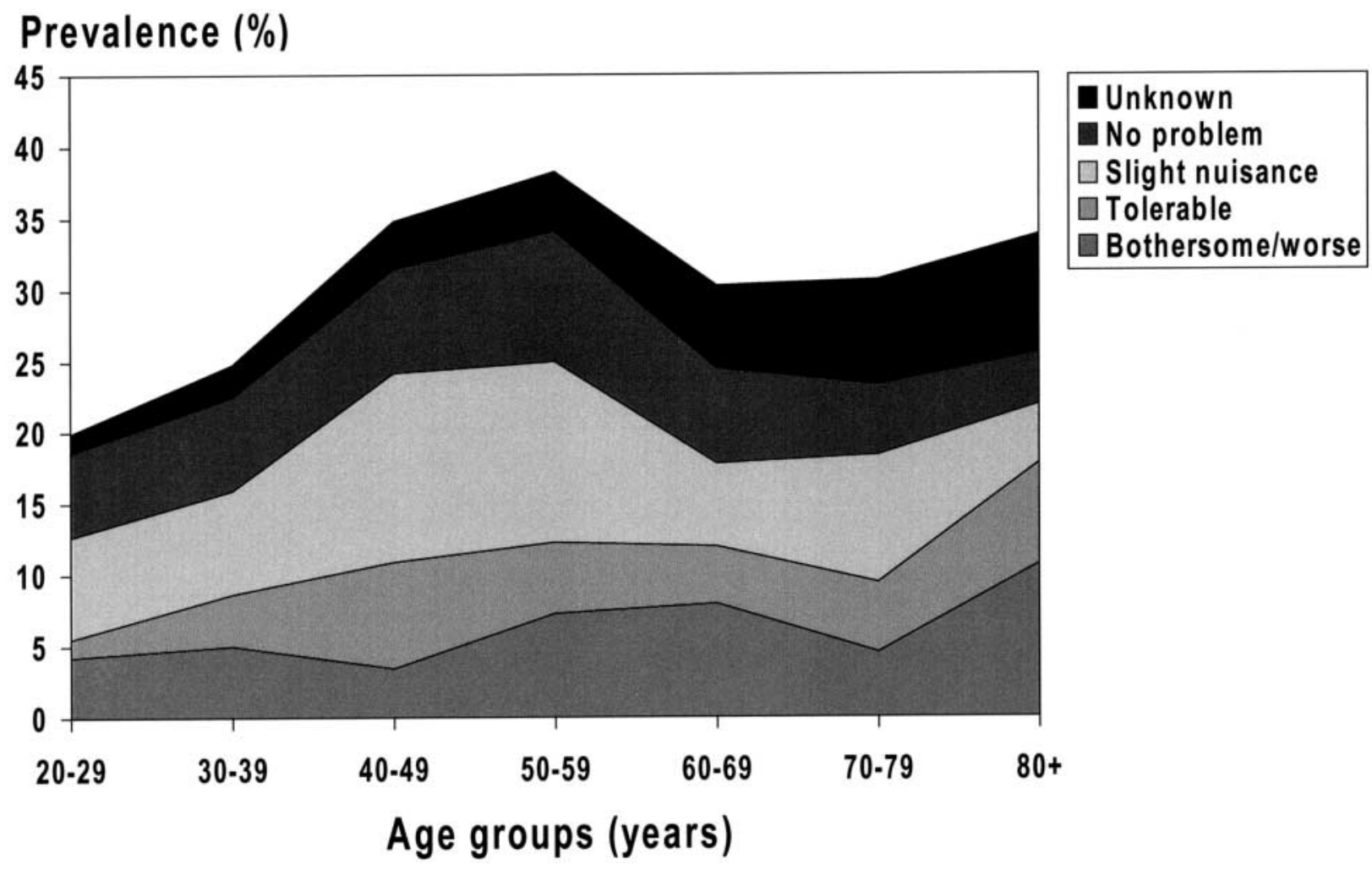

Fig. 4. Prevalence of UI when different thresholds for nuisance are considered. (Data from [58], with permission from H. Sandvik.)

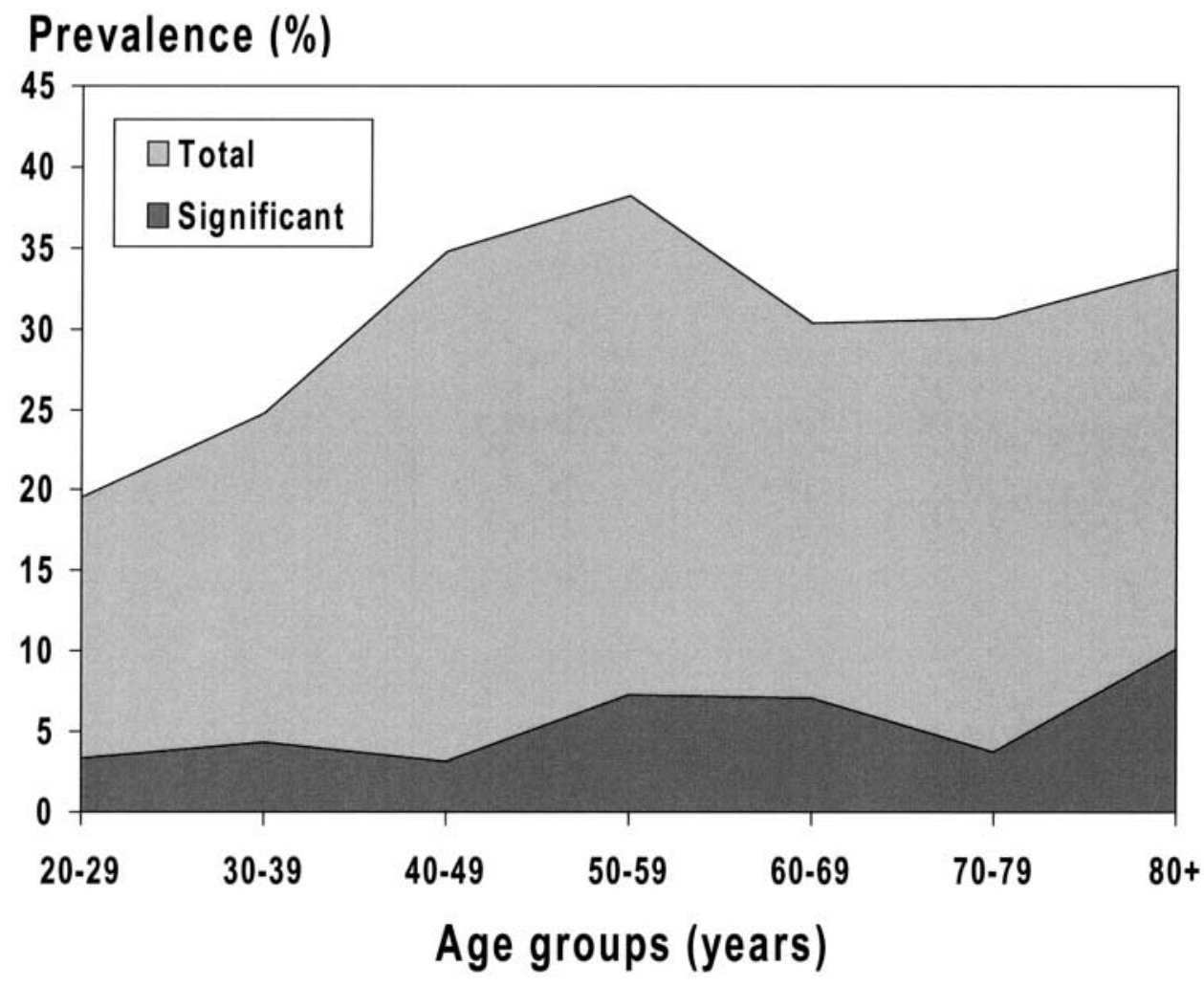

Fig. 5. Prevalence of UI when different thresholds for severity and nuisance combined are considered. Significant incontinence is defined here as either moderate or severe (see Fig. 3) combined with the impact of bothersome or worse (see Fig. 4). (Data reanalyzed from [63], by H. Sandvik.) 


\section{Incidence, Remission and Natural History}

A woman reporting symptoms of UI and seeking treatment for incontinence is presenting with a condition that represents exposure to a number of promoting and decompensating factors. The epidemiological data show that we know relatively little about the development or natural history of the disorder. Data are needed regarding the transition from continence to various levels of severity and types of incontinence. The findings of Thomas and Yarnell [41,64] illustrate the current gap in our knowledge regarding the natural history of UI: as many as one-third of the incontinent respondents became continent again over time.

Few studies have reported on the incidence of UI. Burgio [60] examined a cohort of healthy middle-aged women over 3 years. Of the previously continent women, $8 \%$ of the 206 studied reported at least monthly leakage. A New Zealand study of community-dwelling individuals aged 65 or older found that $10 \%$ of the originally continent adults developed UI in the 3-year study period [48]. This is in contrast to the 1-year incidence of $20 \%$ for older women from another study [65].

Likewise, remission rates (the probability of previously incontinent persons becoming continent) vary considerable across the few studies that have investigated them (for review see [33]). One study showed a 1year remission rate of $12 \%$ for older women [65]. Rates of change are affected by the quality of the measures. Resnick [66] reported low test-retest reliability in reports of incontinence over a period of 2 weeks, whereas others [33] found reasonable test-retest reliability between the beginning and the end of the questionnaire.

In summary, longitudinal studies of incidence, remission and natural hisory are scarce and should be encouraged. It seems well documented that remission can take place, but we do not know much about the predictors for it. It may be natural or related to medical care, but we cannot exclude that unreliable measurements also may play a role.

\section{Racial and Ethnic Differences}

Most epidemiological studies of UI have been conducted in white populations, but some comparative data exist and provide some evidence that white women may be more susceptible to UI than black women.

Some early studies examined UI predominantly in the black African populations. Reports by Heyns [67,68] state that black South Africans rarely developed stress incontinence, and developed the related disorder of pelvic floor prolapse at a rate 80 times lower than whites. Later studies of South African women attempted to explain the rarity of stress incontinence among blacks as a function of differing urethral pressures and lengths, as well as pubococygeal muscle strength $[69,70]$. No difference in the prevalence of minor nulliparous stress incontinence among white (46\%), Indian (42\%) and black South African nurses $(40 \%)$ was demonstrated. Whereas pelvic floor prolapse has been reported to be exceedingly rare among black South Africans it is the most common indication for major surgery in the Pokot people along the Kenyan Ugandan border [71]. Finally, a survey of 100 consecutive native Africans aged 16-60 attending a gynecology clinic in Ghana revealed an overall UI prevalence of $29 \%: 13 \%$ stress and $16 \%$ urge incontinence [72]. Of these, only 5\% had significant associated social or hygienic problems.

In the United States, the Establish Populations for Epidemiologic Studies of the Elderly reported an equal prevalence of UI among both races [73]. In contrast, Burgio et al. [60] reported significant differences in regular and infrequent incontinence in black subjects (18\% and $15 \%$, respectively) compared to white subjects (32\% and $28 \%$ ). However, only 51 of 541 subjects in this study were African American. In a clinical study of patients referred for evaluation of UI or prolapse, Bump and colleagues [74] found that a larger proportion of white women reported symptoms of stress incontinence (31\% vs. $7 \%$ ), and a larger proportion were diagnosed urodynamically as having genuine stress incontinence $(61 \%$ vs. $27 \%)$. In this report, white subjects had a prevalence of pure genuine stress incontinence 2.3 times greater than black subjects. This difference in physiologic subtypes was supported by a recent presentation of similar studies confirming a significant difference in the

Table 7. Some prevalence studies in non-caucasian women

\begin{tabular}{|c|c|c|c|}
\hline Author & Ref. & Country & Prevalence data \\
\hline Lara 1994 & [39] & New Zealand & $\begin{array}{l}\text { Maori women } 47 \% \text {, } \\
\text { Pacific Island women } \\
29 \% \text {, European women } \\
31 \%\end{array}$ \\
\hline Ju 1991 & {$[155]$} & Singapore & $\begin{array}{l}\text { Over all } 4.5 \% \text { in women } \\
>65 \text { years. Malay } \\
\text { Singaporians } 1.1 \% \text {, } \\
\text { Indian } 1.6 \% \text { and Chinese } \\
5.2 \%\end{array}$ \\
\hline Shershah 1989 & {$[156]$} & Pakistan & $\begin{array}{l}\text { Less UI in women } \\
\text { voiding in squatting } \\
\text { posture }(12 \%) \text { than those } \\
\text { using commode type of } \\
\text { toilet }(29 \%)\end{array}$ \\
\hline Lee KS 1991 & [157] & Singapore & $5 \%$ in women $65+$ \\
\hline Essel & {$[72]$} & Ghana & $\begin{array}{l}\text { Prevalence } 29 \%, 13 \% \\
\text { stress and } 16 \% \text { urge }\end{array}$ \\
\hline Brieger 1997 & [158] & Hong Kong & $\begin{array}{l}10 \% \text { stress incontinence, } \\
1 \% \text { urge incontinence }\end{array}$ \\
\hline Kato 1986 & [159] & Japan & $\begin{array}{l}9 \% \text { over all, ranging from } \\
3 \% \text { in age group } 60-69 \text { to } \\
23 \% \text { in age group } 20-29 . \\
\text { Strong association to } \\
\text { parity. }\end{array}$ \\
\hline Fukui 1986 & {$[160]$} & Japan & $\begin{array}{l}32 \% \text { over all, maximum } \\
\text { of } 48 \% \text { in age group } 40- \\
49\end{array}$ \\
\hline Nakanishi 1997 & {$[161]$} & Japan & $\begin{array}{l}10 \% \text { in community- } \\
\text { residing women }>65\end{array}$ \\
\hline
\end{tabular}


predominance of stress incontinence in the white subjects [75]. This difference may, however, be explained by racial differences in help-seeking behavior.

Racial differences have also been reported among pregnant women, but these were evident only for stress incontinence and not for urge incontinence or other types of urine leakage [76].

Some of the studies of non-caucasian women are reviewed in Table 7 . In summary, there remains a paucity of information regarding UI in non-caucasian women worldwide. The existing data are contradictory and plagued by small sample sizes. Given the variable nature of race around the world, these data may therefore not apply to the general population. The only large, scientifically sound epidemiologic study that included a substantial number of blacks asked only one question about UI. The existing data do suggest that UI among blacks is not as rare as anecdotal reports indicate. The available reports indicate a significant difference in the distribution of physiologic subtypes. This lack of knowledge about the prevalence, incidence and natural history and differences in distribution of physiologic subtypes in the non-caucasian population has important implications. For example, if assessment of stress incontinence is less accurate in black women, this would have consequences for research as well as clinical practice [77]. Further worldwide data on non-caucasian population are needed.

\section{Potential Risk Factors}

Epidemiological studies conducted in various populations reveal a number of variables related to UI, including several possible risk factors or contributing variables (Table 8). Most of the data regarding risk factors for the development of UI have been derived from cross-sectional studies of volunteers and clinical subjects. Risk factors such as smoking, obesity, the menopause, restricted mobility, chronic cough, chronic straining for constipation, and urogenital surgery have not been as rigorously studied as have parity and age. This provides us with information of limited generalizability and restricts the level of inference regarding causality.

Well controlled analyses of potential risk factors and predictors are limited. Little is known about their relative

Table 8. Potential risk factors for UI in women reviewed in this text

\section{Age}

Pregnancy

Childbirth

Menopause

Hysterectomy

Obesity

Urinary symptoms

Functional impairment

Cognitive impairment

Occupational risks

Other factors and absolute value. Risk factors or causes of UI need to be investigated in a prospective or longitudinal design in order to establish the temporal ordering between risk factors and the onset of UI. Unfortunately, very few longitudinal studies of UI have been conducted. Therefore this review of health-related factors is based on cross-sectional studies and can only identify correlates.

Age. Because UI is so common among older women it is often regarded as a normal and inevitable part of the aging process. Most studies indicate that UI is indeed correlated with age [40-42,44,78-81]. In one well known study a random sample of 842 women aged 17-64 years were interviewed [42]. The prevalence rates were found to increase steadily with age. In another large survey the prevalence of UI in women 46-86 years old increased progressively over seven birth cohorts (1900 1940) from $12 \%$ to $25 \%$ [40]. Incontinence should not be considered normal with aging; however, there are changes in the bladder and the pelvic structures that occur with age and which can contribute to UI [57,8285]. Further, UI is often attributable to medical problems or diseases that can disrupt the mechanisms of continence (e.g. diabetes mellitus), many of which are more common in older adults.

Pregnancy. UI in women is often assumed to be attributable to the effects of pregnancy and childbirth. The literature shows that UI is more common in pregnant women than in other groups of women. Prevalence rates of $31 \%, 46 \%$ and $60 \%$ have been reported in three separate studies [76,86,87]. For most women UI during pregnancy is self-limiting. However, there is some speculation that women who are incontinent during pregnancy may be predisposed to UI later in their lives, such as during a subsequent pregnancy, or as they age. Indeed, during clinical interview older women will often associate the onset of their incontinence as being concomitant with pregnancy.

Childbirth. The role of childbearing in predisposing women to UI is supported by several studies that have demonstrated a link between UI and parity $[41,43,47,62,76,80,88-91]$. There are several explanations that may be offered. First, childbirth may result in pelvic floor laxity as a consequence of weakening and stretching of the muscles and connective tissue during delivery. Secondly, damage may occur as a result of spontaneous lacerations and episiotomies during delivery. The result of these events can be impaired support of the pelvic organs and alteration in their positions. A third possibility is that the stretching of the pelvic tissues during vaginal delivery may damage the pudendal and pelvic nerves, as well as the muscles and connective tissue of the pelvic floor, and interfere with the ability of the striated urethral sphincter to contract promptly and efficiently in response to increases in intra-abdominal pressure or detrusor contractions. 
The evidence of the relationship between childbearing the UI is presented in several studies. For example, Thomas and colleagues [41] reported that UI was most likely to occur in parous rather than nulliparous women at all ages (15-64), being most common in women who had 4 or more children. Holst and Wilson [48] found that UI was less common in nulliparous women, but found no association between rates of UI and increasing parity. In another study, Jolleys [43] suggested that the relationship between increasing rates of UI and increasing parity was linear. In addition, pregnant women with UI were found by one study to have a history of more pregnancies and more births than pregnant women who were continent [76]. Vaginal delivery in particular is believed to cause pelvic neuropathy that could instigate UI [9293].

Only 3\% of women were found to have troublesome stress incontinence 1 year after their first vaginal birth [94]. This association between childbirth and UI diminishes with age. Foldspang [91] found that, although parity was a risk for stress incontinence, the effect decreased with age. Holst Wilson [48] reported that nulliparous women reported UI less than women with 1 child, but that UI changed insignificantly with increasing parity. Two studies of middle-aged women found no association between parity and UI. Hording and colleagues [88] found that the frequency of UI in 45year-old women was not associated with frequency of births. Similarly, Burgio and colleagues [60] found that healthy perimenopausal women with UI were no more likely to have delivered more children than were continent women. The relationship between pregnancy, childbirth and UI requires further study.

There have been anecdotal reports that the position for vaginal delivery may have a possible impact on UI risk. Vesicovaginal fistula, usually due to obstetric trauma, is an important cause of disastrous UI in developing countries [95]. Differences in birthing practices worldwide (including route of delivery and the availability of obstetric care) should be investigated to determine their potential relationship to continence status.

Menopause. Clinically, it has long been understood that urinary symptoms are an integral part of the transition from the premenopausal to the postmenopausal state. The atrophic changes increase susceptibility to urinary tract infections and cause storage symptoms (such as urinary frequency, urgency), dysuria, vaginal dryness and dyspareunia. Given the evidence that atrophy of these tissues can be reversed with estrogen, and that in some cases estrogen replacement reduces UI, it seems reasonable to suggest that estrogen loss contributes to the problem.

However, the literature is inconsistent in describing the role of the menopause and estrogen loss as significant contributors to UI. Positive findings were reported by Rekers and colleagues [44], who compared premenopausal women $(n=355)$ with postmenopausal women $(n=858)$ and found no significant difference in the prevalence of UI between the two groups $(25 \%$ versus
$26 \%$ ). However, there were significant differences in the frequency of incontinence episodes, indicating that postmenopausal women had more severe incontinence. Postmenopausal women were more likely to have UI on a daily basis or more frequently (7\%), compared to the premenopausal women $(3 \%)$. They were also much likely to have urgency $(P<0.05)$ and nocturia $(P<0.05)$. Postmenopausal women were, however, less likely to have large-volume accidents, and there were no differences in the types of UI. These investigators also examined the timeframe between menopause and the onset of UI. A significant increase in the incidence of UI occurred 10 years before the menopause, and an even larger increase was found at menopause. Among postmenopausal women with UI, $28 \%$ had onset before menopause, $18 \%$ around the time of menopause, and $54 \%$ after menopause. Finally, women who experienced a surgical menopause had a higher rate of UI (36\%) than those whose menopause was natural $(22 \%)$.

One study of menopause status found that among 45year-old women the frequency of UI was no higher in those who were postmenopausal than in those who were premenopausal [88]. A second study found that postmenopausal women were actually less likely to have UI on a regular basis [60]. A third study showed a significantly lower prevalence rate among postmenopausal women $(35 \%)$ than in premenopausal women $(47 \%)[43]$.

Hysterectomy. Well controlled prospective studies investigating the role of hysterectomy are few. Thus the role of hysterectomy is controversial [96,97]. However, when asked about the onset of UI many women will report that it began immediately following hysterectomy. A hysterectomy with oophorectomy puts a woman into surgical menopause, which may imply a hormonal mechanism as the primary cause of UI. Recently, with the development of neurophysiological investigations to measure neurologic impairment of the pelvic floor, the question has been raised whether the development of posthysterectomy UI might be caused by nerve damage during the procedure. It may also be due to disturbances of musculofascial attachments of the bladder to the surrounding pelvic wall.

Milson and colleagues [40], in a survey of 3896 women, reported that those who had a hysterectomy were more likely to report UI than those who had not $(21 \%$ vs. $16 \%)$, and that this trend occurred across five birth cohorts from 1900 to 1920 . Further study of the relationship of hysterectomy to UI could yield surgical techniques that would reduce the incidence of UI.

Obesity. Obesity is often viewed as a factor that can cause UI or contribute to its severity. It is believed that the added weight of obesity, as in pregnancy, may bear down on pelvic tissues, causing chronic strain, stretching and weakening of the muscles, nerves and other structures of the pelvic floor. Anecdotally, patients are known to report improvements in the symptoms of UI 
associated with weight loss, and increased severity with weight gain. In addition, there is clear epidemiological support for the role of obesity in UI.

UI in women has been associated with higher body mass index (BMI) [60,96,98] and greater weight $[79,89]$. In one study a significant relationship was found between UI and BMI such that women with regular UI had the highest mean BMI and those who had never been incontinent had the lowest [59]. Dwyer and colleagues [99] found that obesity was significantly more common in women with detrusor instability, as well as those with stress incontinence, than in continent women. Similarly, in another study obesity was found to be an independent risk factor for incontinence [100]. Other investigators found no differences between continent and incontinent women as regards body mass index [101]. However, they did find that women with a positive stress test (i.e. clinically demonstrated loss of urine with physical stress [coughing]) had a higher BMI than those who had a negative stress test.

In addition to the associations found between obesity, BMI and UI, confirmatory results have been reported for intervention studies. Bariatric surgery was used in one study to drastically reduce weight in a group of morbidly obese women [102]. As a group, the women had both subjective and objective resolution of stress as well as urge incontinence. In another study, weight reduction by bariatric surgery resulted in reduction of stress incontinence from $61 \%$ to $12 \%$ of the group [103]. Thus, there is strong evidence to support the causal role of excess weight in the development of UI. A link between body mass and UI supports the concept that weight gain may increase susceptibility to incontinence, and suggests that weight loss may decrease incontinence.

Lower Urinary Tract Symptoms (LUTS). Irrespective of whether they are due to disease or to normal aging, urinary tract symptoms such as blood in the urine, cloudiness or a foul smell in the urine, burning during urination, difficulty initiating urine flow, inability to stop urine flow, needing to push and strain while urinating, or needing to urinate more than once to empty the bladder, emerge as one of the most critical set of correlates and potential precursors of UI from the analysis of the MESA data [57]. UI is further related to fecal incontinence [57].

Functional Impairment. Another set of health-related correlates that have been substantiated in several studies are functional impairments, particularly mobility limitations [57,104-107]. Mobility problems include having experienced a fall during the last 12 months, being diagnosed with arthritis, currently using equipment to get around, being restricted from going out, and several performance measures of lower-body physical functions. The term dependent continence denotes a condition where the patient is dry but only as a result of being regularly reminded or shown where the toilet is, or requires physical assistance in transferring, mobilizing and/or toileting [108]. The exact interpretation of the relationship between functional impairment and UI, however, is still being debated. At issue is whether UI is a direct consequence of difficulties in getting to the bathroom and removing clothing or, alternatively, whether mobility limitations and UI are both consequences of the general frailty of older age, or of an underlying systemic illness such as a stroke. Longitudinal information is needed to clarify the direction of causation between functional impairments and UI.

Cognitive Impairment. Studies in nursing homes have suggested a link between dementia and UI [109-112], but no relationship between mental status and difficulty in holding urine was found in a community sample [113]. A systematic review of 11 studies examining the rate of UI in patients with dementia [114] concluded that UI is common in such patients, and is more prevalent in demented than in non-demented older people. It occurs with equal or greater frequency in males than in females, and this contrasts with the female preponderance in community-based, general older populations. The association between UI and dementia has been strengthened by systematic psychiatric examination and classification [115].

Occupational Risks. There is currently a dearth of knowledge to aid medical providers in advising their patients about occupational factors that promote either the onset or the recurrence of urinary incontinence.

Other Factors. Other published articles have reported correlations between UI and several other variables, including cystitis or urinary tract infections [35,98], previous gynecological surgery [43,47], constipation [116], the use of diuretics [80], other drugs [117], perineal suturing [43], exercise [118], cystocele [88], uterine prolapse [88], radiation [119], impaired function of the levator muscles [88], childhood bedwetting [27], and current and former cigarette smoking [120]. A recent observational study [121] reviewed the medical records of 5986 members aged 65+ of a large health maintenance organization in California. There was an increased risk of UI associated with the diagnoses of Parkinson's disease, dementia, stroke, depression and congestive heart failure.

\section{Epidemiology of UI in Men}

The epidemiology of UI in men has not been investigated to the same extent as for women. However, sex differences are observed in almost all studies that have examined this. It appears that UI is at least twice as prevalent in women as in men. Type and age distribution are much different between the sexes, and risk factors, although less investigated in men, also seem to be different. We have found no reviews of the epidemiological studies of male UI.

It is also important not to consider UI as an isolated problem in men, as other urogential symptoms, such as 
weak stream, hesitancy, dribbling or impotence, often coexist. Terminal dribbling of urine is a common symptom, but bears no direct correlation with obstruction.

\section{Prevalence}

Some of the major reviews also discuss the prevalence of UI in men [29,30,33]. Table 9 shows examples of the prevalence of at least some degree of UI as found in some studies. There are no studies reporting prevalences for men according to the ICS definition, but for any definition there seems to be a steadier increase in prevalence with increasing age (Table 10) than in women.

Owing to differences in the pathological anatomy and pathophysiology of UI in men, there is a different distribution in incontinence subtypes. Most studies find a predominance of urge incontinence $(40 \%-80 \%)$, followed by mixed forms of UI $(10 \%-30 \%)$ and stress incontinence $(<10 \%)[33,57,122]$. Most studies have a large fraction of other/unclassified types. When it comes

Table 9. Examples of prevalence in studies of at least some degree of UI in men

\begin{tabular}{lclc}
\hline Author & Reference & $\begin{array}{l}\text { Year of } \\
\text { publication }\end{array}$ & \% Prevalence \\
\hline Yarnell & {$[64]$} & 1979 & 11 \\
Feneley & {$[38]$} & 1979 & 3 \\
Thomas & {$[41]$} & 1980 & 9 \\
Schulman & {$[122]$} & 1997 & 9 \\
Malmsten & {$[123]$} & 1997 & 9 \\
\hline
\end{tabular}

Table 10. Examples of prevalence of UI across the age spectrum in men

\begin{tabular}{lllr}
\hline $\begin{array}{l}\text { Author } \\
\text { Reference) }\end{array}$ & $\begin{array}{l}\text { Year of } \\
\text { publication }\end{array}$ & $\begin{array}{l}\text { Distribution } \\
\text { by age }\end{array}$ & \% Prevalence \\
\hline Yarnell [64] & 1979 & 65 & 9 \\
& & $70-80$ & 8 \\
Feneley [38] & 1979 & $80+$ & 22 \\
& & $15-64$ & 2 \\
Thomas [41] & 1980 & $65+$ & 6 \\
& & $45-54$ & 5 \\
& & $55-64$ & 9 \\
& & $65-74$ & 15 \\
Diokno [57] & 1986 & $60+$ & 18 \\
Malmsten [123] & 1997 & 45 & 19 \\
& & 50 & 4 \\
& & 60 & 4 \\
& & 70 & 5 \\
& & 75 & 7 \\
& & 80 & 10 \\
Schulman [122] & \multirow{2}{*}{1997} & $90+$ & 20 \\
& & $45-49$ & 28 \\
& & $50-54$ & 2 \\
& & $60-64$ & 5 \\
& & $70+$ & 6 \\
\end{tabular}

to severity, the gender differences seem to be no different from those for any type of incontinence. Estimates for severe UI in older women tend to be about twice as high as for older men [33]. We have found no studies addressing racial or ethnic differences in the prevalence of UI in men.

Literature on the incidence of male UI is very scarce. The MESA study [65] found a 1-year incidence rate for elderly men of $9 \%$. Substantial remission rates were also obtained, rates that were higher among men $(27 \%)$ than women $(11 \%)$. One likely explanation of the relative instability of male UI focuses on the predominance of urge incontinence in men. Urge UI is often caused by prostate gland disease, infections or bowel dysfunction, all of which are relatively amenable to treatment, or improve even without treatment.

Malmsten [123] analyzed the age of onset for each age cohort. The mean debut age for all men was 63 years and mean duration was about $8-10$ years in the cohorts.

\section{Potential Risk Factors}

There is relative little research concerning conditions and factors that may be associated with UI in men, and clear risk factors are more seldom scientifically documented (Table 11). However, a few studies have identified potential risk factors, which are described below.

As for women, increasing age is correlated with increasing prevalence of UI. There seems to be a more steady increase in prevalence with increasing age than for women.

In a telephone survey of 150 community-living incontinent men aged 20 and over, about $70 \%$ had experienced a variety of other medical conditions, many of which may cause or aggravate UI [124]. About half of the men reported symptoms of bladder outlet obstruction, and almost a third had undergone prostatectomy. In a study of 805 non-institutionalized elderly men, Diokno and coworkers [57] found that a variety of problems, conditions and symptoms are more prevalent among those with UI than those among those without. UI was reported by only $15 \%$ of men without voiding symptoms, frequency or urgency, and by $34 \%$ of those with symptoms. When outlet obstruction is established this may lead to increasing postvoid residual urine, which may lead to chronic retention and manifest as overflow incontinence. Established outlet obstruction may cause detrusor instability, and manifest as urgency, frequency and urge incontinence.

Table 11. Risk factors for UI in men reviewed in this text

Age

Lower urinary tract symptoms

Functional and cognitive impairment

Neurological disorders

Prostatectomy

Other factors 
Mobility problems, such as the use of a wheelchair or walking aids, as well as diagnosed arthritis or rheumatism or having a fall in the last year, were significantly greater in incontinent than continent men [115]. In general, most studies find similarities between men and women (see below) for functional and cognitive impairment as risk factors for UI.

Many specific neurological diseases may lead to UI [124]. Detrusor hyperreflexia is commonly seen in mengingomyelocele patients and in spinal injuries, Parkinson's disease and multiple sclerosis. Areflexic bladder dysfunction due to a cauda equina lesion or diabetes might cause overflow or a paralyzed pelvic floor, and hence stress incontinence.

A well known iatrogenic cause of male incontinence is prostatectomy. The reported incidence of stress incontinence following TURP is about $1 \%$. Figures from radical prostatectomy technique range from $5 \%$ to $34 \%$. Three known risk factors are pre-existing bladder and sphincter dysfunction [126,127], increasing age [128] and lack of surgical expertise [129]. Overall, this type of UI tends to improve with time [130].

\section{Why do Prevalence Estimates Differ?}

The well documented variation in prevalence estimates is thought to result at least in part from several confounders common to survey and epidemiologic research. Herzog and Fultz [131], in a review of the prevalence and incidence of UI in community-dwelling populations, proposed that past investigations were plagued by sampling and non-response issues, by selfselection and attrition, and by definitional, conceptual and measurement issues. These are reviewed briefly below; more comprehensive reviews about measurements and methodological aspects of investigating UI are provided in references 29,32, 132 and 133. It is clear that there are large methodological challenges to rigorous research in this field. Unless the scientific community deals with these challenges, progress will be difficult to achieve.

\section{Different Definitions and Measurement}

A major problem in research on UI has been the use of different definitions and measurements, and this might contribute to the wide range of reported prevalence estimates. The ICS definition of UI - a condition in which involuntary loss of urine is a social or hygienic problem and is objectively demonstrable $[1,134]$ includes objective demonstration of urine loss as one critical component. This aspect limits the ICS definition for community-based epidemiologic investigations, because objective demonstration of UI is difficult to achieve outside the clinical setting, and studies that were able to include this aspect in their assessment might have produced different prevalences. In addition, the social or hygienic aspect of the ICS definition might be problematic in epidemiologic studies because it adds a subjective aspect to an objectively defined condition, and therefore confounds the investigation of prevalence, incidence and risk factors. By the same token, the subjective definition of a problem or nuisance might be relevant in the investigation of care-seeking for UI, and the prediction of who is likely to become a patient for this condition. Again, inclusion of this aspect into the definition might lead to different prevalence estimates. Also, studies have used different objective severity levels for defining UI: whereas some classify any involuntary loss at all as UI, others require at least monthly, weekly or even daily loss for UI classification. Moreover, different timeframes for the occurrence of involuntary urine loss have been used in existing studies. Loss during the previous week, month, 6 or 12 months have been used; sometimes the time period is left unspecified. As UI symptoms can occur irregularly, a timeframe for measurement must be established. Finally, varying efforts have been expanded to overcome a social desirability bias, according to which respondents tend to underreport UI unless strongly encouraged to be honest and forthcomingly. For future community-based epidemiologic research we propose that the core definition of UI should include only the involuntary nature of the urine loss and the objectively defined severity of the condition by symptoms of frequency or quantity of loss. We also recommend that a time period for observing the symptoms should be specified, and that patients should be encouraged to report honestly.

A further factor complicating the conceptualization and measurement of UI in epidemiologic studies lies in the nature of the condition. UI is a chronic condition (or set of conditions) that often starts slowly and comes and goes for a considerable time before it become fully established [132]. Moreover, over time people get used to their UI and notice it less. These aspects can interfere with valid assessment.

Ideally self-reporting measures are validated by clinical evaluation. However, clinical and even urodynamic investigations should be regarded as other measures, not necessarily as gold standards, because it is known to be difficult to demonstrate all urinary symptoms in the clinical setting. Some validation investigations have been reported. Diokno et al. [56] invited both continent and incontinent respondents from a community survey for extensive clinical investigations, and found $83 \%$ agreement between self-reports of UI and the clinical assessment. Two Swedish studies have reported that $5 \%$ and $6 \%$ of self-reported UI could not be verified in the clinic [40,135]. A recent study [136] revealed less than satisfactory predictive validity of selfreported types of UI compared with urodynamic investigations. The time delay between the two measures in these investigations may explain some of the lack of agreement.

Holtedahl [137] calculated prevalence estimates using different definitions of UI for the same sample of 50-70year-old women. The prevalence of any self-reported leakage was $47 \%$. Self-reported regular UI, with or 
without objective demonstration, was found in $31 \%$ of women, and regular incontinence according to the full ICS definition in $19 \%$. The results indicate that the ICS definition is rather restrictive and yields prevalence estimates lower than many other definitions used in epidemiologic studies.

\section{Sample and Data Collection Methodology}

Some surveys, mostly British, have selected their samples from lists of patients in general practice $[41,43,47,138,139]$. These surveys usually get good response rates, but unless such lists include all persons in the population they are biased sampling frames [33]. Some population-based studies have included institutionalized patients [40,135], some have excluded them [42,57], and other authors have provided no information on this issue $[42,48]$. The differences will obviously account for some of the variation in prevalence estimates observed among older women.

Low response rates may further bias prevalence estimates [132,140]. Known differences between responders and non-responders can be compensated for during the analysis. The major problem is unknown differences [140] in response rates and other characteristics. Incontinent women may not answer (or deny UI) because of embarrassment or related handicaps. Equally, incontinent women may find the subject particularly relevant and therefore respond to a greater extent than continent women. At present, we do not know how these factors may affect the comparison between incontinent and continent women.

Data on UI are often collected by post, but some authors have conducted personal or telephone interviews. Personal interviews allow the exploration of issues in greater detail and achieve generally higher response rates than postal questionnaires. There is also the possibility that responses elicited by interview are more susceptible to social desirability bias than those elicited by post.

\section{Help-Seeking Behavior}

A majority of people with UI have not sought help [122,141-144]. In a Norwegian study $4.4 \%$ of all women over 20 years old in a community consulted their GP for UI during a 3-year period [145]. Increasing age, increasing severity, increasing duration and urge/mixed UI were shown to be associated with consulting a doctor [142].

The most commonly used method of actively managing UI among community residents is the use of absorbent products [122,141,146-148]. Only a small proportion of incontinent community-dwelling women have used surgery, medication or exercise regimens $[141,142]$. The only factor that appears reliably related to whether any treatment or management is sought is the severity of the condition [141] (for review see [29]). It is also probable that many primary health-care providers lack confidence in managing UI, and that this contributes to undertreatment in those seeking help [149].

It is obvious that millions of men and women suffer from their UI, and that for many of them good treatment can be offered. However, for many with very mild or occasional UI it is probably adequate not to seek help. Others are satisfied with just information and understanding about the causes, and self-care may be quite appropriate [143]. A Danish study has also shown that simple information and advice was adequate for $23 \%$ of the women visiting an open-access incontinence clinic [150].

It is important to realize that many incontinent persons have never talked to a health-care professional about the condition. Both epidemiological and qualitative research in this field should be encouraged in order to understand cultural, religious and other reasons for help-seeking behavior worldwide.

\section{Epidemiology and Clinical Work: From Respondent to Patient}

In this paper we have emphasized some major and important differences between epidemiology and clinical work which may have several implications. A selection process is most often accomplished first by self-selection (help-seeking), then by a referral system, which provides specialist physicians with a patient population with a higher prevalence of disease, more severe disease, and often a skewed-type distribution, thus obtaining test results with fewer false positives, better diagnostic accuracy and more efficient use of resources. However, such intended and deliberate selection bias has its drawbacks. There is growing evidence that it introduces a serious bias into research and hampers our ability to generalize hospital-based research back to primary health-care populations. Furthermore, it may result in recommendations and guidelines for diagnosis or therapy derived from tertiary care centers which are inappropriate at the primary care level [151]. Often guidelines, review articles or teaching material do not take into account the varying prevalences and variations in the clinical picture between community and hospital. They may also emphasize the use of tests or equipment that are not appropriate or relevant for general practice and primary health care, thus leading to the overuse of referral. Data from hospitals or specialists may also overestimate the amount of burden, costs and number of persons in need of treatment if such data are used for extrapolation back to community level.

One study provides substantial empirical evidence to support the existence of selection bias for UI [151]. The analyses were based on three populations of incontinent women: community level (epidemiological survey), primary care level (prospective study) and secondary care level (university hospital, prospective study). The 
general practice patients were older and the hospital patients younger than those in the community. From community via general practice to hospital there was an increase in duration, frequency of leakage, amount of leakage, severity and perceived impact of incontinence. Help-seeking at the primary care level was associated with increasing age and severity, and with urge symptoms and substantial impact. Referral from general practice to hospital level was only associated with (lower) age and urge symptoms.

Earlier we showed how prevalence estimates can change dramatically when the nuisance, frequency and amount of leakage are considered. In addition, there is also selection bias through the health-care system. Taken together, this emphasizes the need for caution when epidemiological data are used in a clinical context. It concerns level of care in several ways: there is a large transitional zone from healthy to diseased, there is a danger of medicalization, and there is a danger of treating patients at a higher level than necessary.

Risk factors, predictors and correlates discovered in epidemiological studies are problematic and may not be decisive in the clinical assessment of an individual patient. In addition, the risk attributable to some known risk factors may be statistically but not clinically significant.

\section{Recommendations for Further Research}

It is recommended that more sustained research is needed on the measurement of UI, its types and severity. Longitudinal study designs are required to estimate the incidence of UI and describe the course of the condition and its different forms, and to investigate its risk factors and possible protective factors.

There is an absence of epidemiological data in developing countries and it is recommended that fundamental research regarding prevalence, incidence and other epidemiological data in such countries should be encouraged, and tailored to the cultural, economic and social environment of the population under study.

Crude prevalence studies (descriptive epidemiology) from the USA and Europe are abundant, and further studies should be done only with recommended and validated questionnaires or in order to combine data from the prevalence study with studies of cofactors and predictors (analytical epidemiology).

Some potential risk and protective factors deserve more attention. For example, the role of childbirth in the development of UI must be studied in a fashion that links population-based methods to clinical assessment of the birth trauma, and follows women over many years. Such a design is necessary because the effect of childbirth will become clear only years later when the woman is older, and because she will not be able to report the exact nature of the tear and the episiotomy, etc. Other potential risk factors include obesity, various forms of stress of the pelvic floor, and smoking. Hormone replacement therapy and physical exercise may have a protective role.
The main goal in the management of human disease is primary prevention. An important strategy would thus be to identify the individuals at risk and then take steps to reduce that risk. However, based on current knowledge there are no well documented measures that can be set up to avoid the occurrence of UI in large populations. Primary prevention studies should be encouraged, but the epidemiological basis for choosing appropriate interventions is weak.

Some specific topics for further epidemiological research could be as follows:

Standardization of measurement instruments for UI in community surveys

Epidemiological research in developing countries

Racial differences

Prospective incidence studies

Search for specified risk factors and protective factors

Prospective cohort studies and case control studies for risk factor assessment

Predictors for remission of UI

Prevalence comparison between several countries, using the same methodology

Barriers to seeking help

Primary prevention.

There is merit in reconsidering the definition of UI, and moving towards a standardization of measurement instruments of UI in community surveys that can be used worldwide. Developing a new definition is a scientific process requiring careful conceptualization of the condition in light of its many clinical presentations and underlying mechanisms. This will require a multimethod approach and consideration of issues such as reliability and validity. Clearly, the core of the definition is 'any involuntary loss of urine'. However, this may require elaboration, depending on the purpose of its use.

For the purpose of epidemiological research it is recommended that the following are included in the definition:

The individual's statement of any involuntary urine loss The frequency of urine loss

The quantity of urine loss

The duration of the condition.

Consistent with standard epidemiological practices, it is not recommended that quality of life or nuisance be included in the definition of UI for epidemiological purposes, as this confounds or distorts our estimates of prevalence and incidence. A second reason is that it could seriously limit the detection of risk factors. However, quality of life or nuisance may be important elements of a definition of UI for clinical purposes.

Variations in definitions and measurement issues are fundamental and lead to problems with assessing the findings in epidemiological studies. It is therefore recommended that all epidemiological studies include a minimum data set with the following elements: 
Screening question for any involuntary urine loss

Frequency measure (for example, classification into categories of none, less than once a month, one/ several times a month, one/several times a week, every day/night, all the time)

Quantity of urine loss for a typical episode (for example, classification into categories of none, drops, small amounts, moderate amounts, much/a great deal)

Duration (months, years).

In addition, it is highly recommended to include validated measures of nuisance/quality of life and symptoms.

This article is based on the work of the subcommittee on epidemiology which reported to the First WHOsponsored Consultation on Incontinence, Monaco 1998. The subcommittee's file report is published in Abrams P, Khoury S, Wein AJ (eds) 1999 Incontinence. Health Publication Ltd.

Acknowledgments. We wish to thank Dr Hogne Sandvik, who let us use data from his thesis, as well as numerous colleagues for their help, comments and suggestions. We are also obliged to the organizers of the First International Consultation on Incontinence, Monaco, 1998, who gave us the opportunity to work together on this work.

\section{References}

1. Abrams P, Blaivas JG, Stanton SL, Andersen JT. The standardization of terminology of lower urinary tract function. Scand J Urol Nephrol 1988;22(Suppl 114):5-19

2. Krantz I, Jylkäs E, Ahlberg BM, Wedel H. On the epidemiology of nocturnal enuresis: a critical review of methods used in descriptive epidemiological studies on nocturnal enuresis. Scand J Urol Nephrol 1994;163(Suppl):75-82

3. Watanabe $\mathrm{H}$, Azuma Y. A proposal for a classification system of enuresis based on overnight simultaneous monitoring of electroencephalography and cystometry. Sleep 1989;12:257-264

4. McGee R, Mackinson T, Williams S, Simpson A, Silva PA. A longitudinal study of enuresis from 5-9 years. Aust Paediatr $J$ 1984;20:39-42

5. Feehan M, McGee R, Stanton W, Silva PA. A 6 year follow-up of childhood enuresis: prevalence in adolescence and consequences for mental health. $J$ Paediatr Child Health 1990;26:75-79

6. Fergusson DM, Horwood LJ, Shannon FT. Factors related to the age of attainment of nocturnal bladder control: an 8-year longitudinal study. Pediatrics 1986;78:884-890

7. Hellström AL, Hanson E, Hansson S et al. Micturition habits and incontinence in 7 year old Swedish school entrants. Eur $J$ Pediatr 1990;149:434-437

8. Swithinbank LV, Carr JC, Abrams PH. Longitudinal study of urinary symptoms in children. Scand J Urol Nephrol 1994;163(Suppl.):67-73

9. Bower WF, Moore KH, Shepherd R, Adams R. The epidemiology of childhood enuresis in Australia. $\mathrm{Br} J \mathrm{Urol}$ 1996;78:602-606

10. Watanabe H, Kawauchi A. Nocturnal enuresis: social aspects and treatment perspectives in Japan. Scand J Urol Nephrol 1994;163(Suppl.):29-38

11. Collet JP, Simon MF, Lochart P. Prévalence de l'enurésie chez l'enfant scolaire. Pédiatrie 1993;48:701-704

12. Jarvelin MR, Vikevainen-Tervonen L, Moilanen J, Huttenen NP. Enuresis in seven year old children. Acta Pediatr Scand 1988;77:148-153
13. Hogg RJ, Husmann D. The role of family history in predicting response to desmopressin in nocturnal enuresis. $J$ Urol 1993;150:444-445

14. Rittig S. Nocturnal enuresis at the molecular level. Scand J Urol Nephrol 1995;173(Suppl.):9-14

15. Eiberg H. Nocturnal enuresis is linked to a specific gene. Scand J Urol Nephrol 1995;173(Suppl.):15-17

16. Steinhausen H-C, Gobel D. Enuresis in child psychiatric clinic patients. J Am Acad Child Adolesc Psychiatry 1989;28:279-281

17. von Gontard A, Hollmann E, Eiberg H et al. Clinical enuresis phenotypes in familial nocturnal enuresis. Scand J Urol Nephrol 1997;183(Suppl.):11-16

18. Rittig S, Knudsen UB, Norgaard JP et al. Abnormal diurnal rhythm of plasma vasopressin and urinary output in patients with enuresis. Am J Physiol 1989;25:664-667

19. Mikkelsen EJ, Rapoport JL. Enuresis: psychopathology, sleep stage and drug responses. Urol Clin N Am 1980;7:361-377

20. Hunsballe JM, Rittig S, Djurhuus JC. Sleep and arousal in adolescents and adults with nocturnal enuresis. Scand J Urol Nephrol 1995;173(Suppl.):59-61

21. Baruzzi A, Riva R, Cirignotta F et al. Atrial natriuretic peptide and catecholamines in obstructive sleep apnoea. Sleep 1991;14:83-86

22. Husmann DA. Enuresis. Urology 1996;48:184-193

23. Ritchley ML, Sinha A, DiPietro MA et al. Significance of spina bifida occulta in children with diurnal enuresis. $J$ Urol 1994; $152: 815-818$

24. Forsythe WI, Redmond A. Enuresis and spontaneous cure rate. Arch Dis Child 1974;49:259-263

25. Swithinbank LV, Brookes ST, Sheperd AM, Abrams P. The natural history of urinary symptoms during adolescence. $\mathrm{Br} J$ Urol 1998;81(Suppl 3):90-93

26. Bengtsson B, Bengtsson M. Childhood enuretics in adult age. A long-term retrospective follow-up of 88 enuretic children. Proceedings of the 3rd International Children's Continence Symposium 1995, pp. 61-63. Wells Medical Ltd. Royal Tunbridge Wells, Kent, UK, 1996.

27. Foldspang A, Mommsen S. Adult female urinary incontinence and childhood bedwetting. J Urol 1994;152:85-88

28. Moore KH, Richmond DH, Parys BT. Sex distribution of adult idiopathic detrusor instability in relation to childhood bedwettiing. Br J Urol 1991;68:479-482

29. Fultz NH, Herzog R. Epidemiology of urinary symptoms in the geriatric population. Geriatr Urol 1996;23:1-10

30. Hampel C, Wienhold D, Benken N et al. Prevalence and natural history of female incontinence. Eur Urol 1997;32(Suppl. 2):312

31. Hampel C, Wienhold D, Benken $\mathrm{N}$ et al. Definitions of overactive bladder and epidemiology of urinary incontinence. Urology 1997;50(6A):4-14

32. Herzog AR, Diokno AC, Fultz NH. Urinary incontinence: medical and psychosocial aspects. In: Lawton MP, ed. Annual review of gerontology and geriatrics. New York: Springer 1989;9:77-119

33. Herzog AR, Fultz NH. Prevalence and incidence of urinary incontinence in community-dwelling populations. J Am Geriatr Soc 1990;38:273-281

34. Mohide EA. The prevalence and scope of urinary incontinence. Clin Geriatr Med 1986;2:639-655

35. Wolin L. Stress incontinence in young, healthy nulliparous female subjects. J Urol 1969;101:545-549

36. Nemir A, Middleton RP. Stress incontinence in young nulliparous women. Am J Obstet Gynecol 1954;68:1166-1168

37. Brocklehurst JC. Urinary incontinence in the community: analysis of a Mori poll. Br Med J 1993;306:832-834

38. Feneley RC, Sheperd AM, Powell PH, Blannin J. Urinary incontinence: prevalence and needs. Br J Urol 1979;51:493-496

39. Lara C, Nacey J. Ethic differences between Maori, Pacific Island and European New Zealand women in prevalence and attitudes to urinary incontinence. NZ Med $J$ 1994;107:374-376

40. Milsom I, Ekelund P, Molander U et al. The influence of age, 
parity, oral contraception, hysterectomy and menopause on the prevalence of urinary incontinence in women. $J$ Urol 1993;149:1459-1462

41. Thomas TM, Plymat KR, Blannin J, Meade TW. Prevalence of urinary incontinence. Br Med J 1980;281:1243-1245

42. Yarnell JW, Voyle GJ, Richards CJ, Stephenson TP. The prevalence and severity of urinary incontinence in women. $J$ Epidemiol Commun Health 1981;35:71-74

43. Jolleys JV. Reported prevalence of urinary incontinence in women in a general practice. Br Med J 1988;296:1300-1302

44. Rekers H, Drogendijk AC, Valkenburg H, Riphagen F. Urinary incontinence in women from 35 to 79 years of age: prevalence and consequences. Eur $J$ Obstet Gynecol Reprod Biol 1992;43:229-234

45. Elving LB, Foldspang A, Lam GW, Mommsen S. Descriptive epidemiology of urinary incontinence in 3,100 women age 30 59. Scand J Urol Nephrol 1989;125(Suppl.):37-43

46. Fall M, Frankenberg S, Frisén M et al. 456000 svenskar kan ha urininkontinens. Endast var fjärde söker hjälp för besvären. Lakartidningen 1985;82:2054-2056

47. Harrison GL, Memel DS. Urinary incontinence in women: its prevalence and its management in a health promotion clinic. $\mathrm{Br}$ $J$ Gen Pract 1994;44:149-152

48. Holst K, Wilson PD. The prevalence of female urinary incontinence and reasons for not seeking treatment. NZ Med J 1988;101:756-758

49. Kok AL, Voorhorst FJ, Burger CW et al. Urinary and fecal incontinence in community-residing elderly women. Age Aging 1992;21:211-215

50. O'Dowd TC. Management of urinary incontinence in women. $\mathrm{Br}$ J Gen Pract 1993;43:426-429

51. Resnick NM, Yalla SV. Management of urinary incontinence in the elderly. $N$ Engl J Med 1985;313:800-805

52. Weiss BD. Nonpharmacological treatment of urinary incontinence. Am Fam Phys 1991;44:579-586

53. Williams ME, Pannill FC. Urinary incontinence in the elderly: physiology, pathophysiology, diagnosis, and treatment. Ann Intern Med 1982;97:895-907

54. Overstall PW, Rounce K, Palmer JH. Experience with an incontinence clinic. J Am Geriatr Soc 1980;28:535-538

55. Resnick NM, Yalla SV, Laurino E. The pathophysiology of urinary incontinence among institutionalized elderly persons. $N$ Engl J Med 1989;320:1-7

56. Diokno AC, Brown MB, Brock BM et al.. Clinical and cystometric characteristics of continent and incontinent noninstitutionalized elderly. J Urol 1988;140:567-571

57. Diokno AC, Brock BM, Brown MB, Herzog R. Prevalence of urinary incontinence and other urological symptoms in the noninstitutionalized elderly. J Urol 1986;136:1022-1025

58. Sandvik H, Hunskaar S, Vanvik A et al. Diagnostic classification of female urinary incontinence: an epidemiologic survey corrected for validity. J Clin Epidemiol 1995;48:339-343

59. Campbell AJ, Reinken J, McCosh L. incontinence in the elderly: prevalence and prognosis. Age Aging 1985;14:65-70

60. Burgio KL, Matthews KA, Engel BT. Prevalence, incidence and correlates of urinary incontinence in healthy, middle-aged women. J Urol 1991;146:1255-1259

61. Mäkinen J, Gronroos M, Kiilholma P et al. Incidence of urinary incontinence in adult Finnish women. Duodecim 1992;108:481485

62. Sommer P, Bauer T, Nielsen KK et al. Voiding patterns and prevalence of incontinence in women. A questionnaire survey. Br J Urol 1990;66:12-15

63. Sandvik H, Hunskaar S, Seim A et al. Validation of a severity index in female urinary incontinence and its implementation in an epidemiological survey. $J$ Epidemiol Commun Health 1993;47:497-499

64. Yarnell JWG, St. Leger AS. The prevalence, severity and factors associated with urinary incontinence in a random sample of the elderly. Age Aging 1979;8:81-85

65. Herzog AR, Diokno AC, Brown MB et al. Two-year incidence, remission, and change patterns of urinary incontinence in noninstitutional older adults. J Gerontol 1990;45:M67-M74
66. Resnick NM, Beckett LA, Branch LG et al. Short-term variability of self report of incontinence in older persons. $J$ Am Geriatr Soc 1994;42:202-207

67. Heyns OS. Urinary incontinence. Clin Proc 1943;2:311-312

68. Heyns OS. Bantu gynaecology. Johannesburg: Witwaterstrand University Press, 1956;98.

69. Skinner DP. Stress urinary incontinence: a comparative racial study. Med Proc 1963;9:189-194

70. Knobel J. Stress incontinence in the black female. $S$ Africa $J$ Obstet Gynaecol 1975;49:430-432

71. Cox PSV, Webster D. Genital prolapse amongst the Pokot. East Africa Med J 1975;52:694-699

72. Essel EK. Prevalence of urinary incontinence among Ghanaian women. Personal communication 1998

73. White LR, Blazer DG, Fillenbaum G. Related health problems In: Cornoni-Huntley J, Blazer DG, Lafferty ME et al., eds. Established populations for epidemiologic studies of the elderly, Volume II. National Institute of Aging, US Department of Health and Human Services, Public Health Service, National Institutes of Health, NIH Publication, 1986; No. 90-495:70-76

74. Bump RC. Racial comparisons and contrasts in urinary incontinence and pelvic organ prolapse. Obstet Gynecol 1993;81:421-425

75. Peacock LM, Wiskind AK, Wall LL. Clinical features of urinary incontinence and urogenital prolapse in a black inner city population. Am J Obstet Gynecol 1994;171:1464-1469

76. Burgio KL, Locher JL, Zyczynski $\mathrm{H}$ et al. Urinary incontinence during pregnancy in a racially mixed sample: characteristics and predisposing factors. Int Urogynecol J 1996;7:69-73

77. US Department of Health and Human Services, Public Health Service. Healthy people 2000: national health promotion and disease prevention objectives. DHHS Pub. No. 91-50213. Washington: US Government Printing Office; 1991

78. Rekers H, Drogendijk AC, Valkenburg HA, Riphagen F. The menopause, urinary incontinence and other symptoms of the genito-urinary tract. Maturitas 1992;15:101-111

79. Krsnjavi H, Uglesic M. Urinary incontinence in female workers in the area of Zagreb. Archi Za Higijenu Reda i Toksikologiju 1991;43:235-238 (abstract)

80. Simeonova Z, Bengtsson C. Prevalence of urinary incontinence among women at a Swedish primary health care centre. Scand J Prim Health Care 1990;8:203-206

81. Lam GW, Foldspang A, Elving LB, Mommsen S. Urinary incontinence in women aged 30-59 years. An epidemiological study. Ugeskr Laeger 1990;152:3244-3246

82. Fantl JAA, Newman DK, Colling J et al. Urinary incontinence in adults: acute and chronic management. Clinical Practice Guidelines No. 2,1996 Update. Rockville, MD: US Department of Health and Human Services. Public Health Service, Agency for Health Care Policy and Research. AHCPR Publication Number 96-0682, March 1996

83. Staskin DR. Age-related physiologic and pathologic changes affecting lower urinary tract function. Clin Geriatr Med 1986;2:701-710

84. Resnick NM. Initial evaluation of the incontinent patient. $J \mathrm{Am}$ Geriatr Soc 1990;39:311-316

85. Diokno AC. Diagnostic categories of incontinence and the role of urodynamic testing. J Am Geriatr Soc 1990;38:300-305

86. Metanyi S. Urinary incontinence in pregnancy and puerperium. Orv Hetil 1992;133:2551-2553 (abstract)

87. Mellier G, Delille MA. Urinary disorders during pregnancy and post-partum. Rev Fr Gynecol Obstet 1990;85:525-528 (abstract)

88. Hording U, Pedersen KH, Sidenius K, Hedegaard L. Urinary incontinence in 45-year-old women. An epidemiologic survey. Scand J Urol Nephrol 1986;20:183-186

89. Yarnell JW, Voyle GJ, Richards CJ, Stephenson TP. Factors associated with urinary incontinence in women. $J$ Epidemiol Commun Health 1982;36:58-63.

90. Crist T, Shingleton HM, Koch F, Koch GG. Stress incontinence and the nulliparous patient. Obstet Gynecol 1972;40:13-17

91. Foldspang A, Mommsen S, Lam GW, Elving L. Parity as a correlate of adult female urinary incontinence prevalence. $J$ Epidemiol Commun Health 1992;46:595-600 
92. Smith ARB, Hosker GL, Warrell DW. The role of pudendal nerve damage in the aetiology of genuine stress incontinence in women. Br J Obstet Gynaecol 1989;96:29-32

93. Snooks SJ, Swash M, Henry MM, Setchel M. Risk factors in childbirth causing damage to the pelvic floor innervation. Int $J$ Colorectal Dis 1986;1:20-24

94. Viktrup L, Lose G, Rolff M, Farfoed K. The symptom of stress incontinence caused by pregnancy or delivery in primiparas. Obstet Gynecol 1992;79:945-949

95. Danso KA, Martey JO, Wall LL, Elkins TE. The epidemiology of genitourinary fistulae in Kumasi, Ghana, 1977-1992. Int Urogynecol J 1996;7:117-120

96. Brown JS, Seeley DG, Fong $J$ et al. Urinary incontinence in older women: who is at risk? Study of osteoporotic fractures research group. Obstet Gynecol 1996;87(5 Pt 1):715-721

97. Thaker R, Manyonda I, Stanton SL et al. Bladder, bowel and sexual function after hysterectomy for benign conditions. $\mathrm{Br} J$ Obstet Gynaecol 1997;104:983-987

98. Mommsen S, Foldspang A. Body mass index and adult female urinary incontinence. World J Urol 1994;12:319-322

99. Dwyer PL, Lee ETC, Hay DM. Obesity and urinary incontinence in women. Br J Obstet Gynaecol 1988;95:91-96

100. Wingate L, Wingate MB, Hassanein R. The relation between overweight and urinary incontinence in postmenopausal women: a case control study. J N Am Menopause Soc 1994;1:199-203

101. Kolbl H, Riss P. Obesity and stress urinary incontinence: significance of indices of relative weight. Urol Int 1988;43:7-10

102. Bump RC, Sugerman HJ, Fantl FA, McClish DK. Obesity and lower urinary tract function in women: effect of surgically induced weight loss. Am J Obstet Gynecol 1992;166:392-399

103. Deitel M, Stone E, Kassam HA et al. Gynecologic-obstetric changes after loss of massive excess weight following bariatric surgery. J Am Coll Nutr 1988;7:147-153

104. Herzog AR, Fultz NH, Brock BM et al. Urinary incontinence and psychological distress among older adults. Psychol Aging 1988;3:115-121

105. Resnick NM, Wetle TT, Scherr P et al. Urinary incontinence in community dwelling elderly: prevalence and correlates (Abstract). Proceeding of the 16th Annual Meeting of the International Continence Society 1986; pp 76-77

106. Tinetti ME, Inouye SK, Gill TM, Doucette JT. Shared risk factors for falls, incontinence, and functional dependence unifying the approach to geriatric syndromes. JAMA $1995 ; 273: 1348-1353$

107. Wetle T, Scherr P, Branch L et al. The prevalence and correlates of urinary incontinence in community dwelling elders. Paper presented at the 114th Annual Meeting of the American Public Health Association. Las Vegas, NV, November 1986.

108. Fonda D (Victorian Geriatrics Peer Review Group). Improving management of urinary incontinence in geriatric centres and nursing homes. Aust Clin Rev 1990;10:66-71

109. Ekelund P, Rundgren A. Urinary incontinence in the elderly with implications for hospital care consumption and social disability. Arch Gerontol Geriatr 1987;6:11-18

110. Ouslander JG, Morishita L, Blaustein J et al. Clinical, functional, and psychosocial characteristics of an incontinent nursing home population. J Gerontol 1987;42:631-637

111. Borrie MJ, Davidson HA. Incontinence in institutions: costs and contributing factors. Can Med Assoc J 1992;147:322-328

112. Ouslander JG, Uman GC, Urman HN, Rubenstein LZ. Incontinence among nursing home patients: clinical and functional correlates. J Am Geriatr Soc 1987;35:324-330

113. Wetle T, Scherr P, Branch LG et al. Difficulty with holding urine among older persons in a geographically defined community: prevalence and correlates. J Am Geriatr Soc 1995;43:349-355

114. Skelly J, Flint AJ. Urinary incontinence associated with dementia. J Am Geriatr Soc 1995;43:286-294

115. Ouslander JG, Palmer MH, Rovner BW, German PS. Urinary incontinence in nursing homes: incidence, remission and associated factors. J Am Geriatr Soc 1993;41:1083-1089

116. Diokno A, Brock B, Herzog A, Bromberg J. Medical correlates of urinary incontinence in the elderly. Urology 1990;36:129-138
117. Montella J, Wordell CJ. The effects of drugs on the lower urinary tract. In: Ostergard D, Bent AE, eds. Urogynecology and urodynamics. Baltimore: Williams and Wilkins, 1996

118. Nygaard IE, Thompson FL, Svengalis SL, Albright JP. Urinary incontinence in elite nulliparous athletes. Obstet Gynecol 1994;84:183-187

119. Parkin DE, Davis JA, Symonds RP. Urodynamic findings following radiotherapy for cervical carcinoma. $\mathrm{Br} J$ Urol 1988;61:213-217

120. Bump RC, McClish DK. Cigarette smoking and urinary incontinence in women. Am J Obstet Gynecol 1992;167:12131218

121. Thom DH, Haan MN, van den Eeden S. Medically recognized urinary incontinence and risks of hospitalization, nursing home admission and mortality. Age Aging 1997;26:367-374

122. Schulman C, Claesm H, Matthijs J. Urinary incontinence in Belgium: a population-based epidemiological survey. Eur Urol 1997;32:315-320

123. Malmsten UG, Milsom I, Molander U, Norlen LJ. Urinary incontinence and lower urinary tract symptoms: an epidemiological study of men aged 45-99 years. J Urol 1997;158:17331737

124. Hunskaar S. One hundred and fifty men with urinary incontinence. I. Demography and medical history. Scand $J$ Prim Health Care 1992;10:21-25

125. Resnick NM, Yalla SV. Detrusor hyperactivity with impaired contractile function: an unrecognised but common cause of incontinence in elderly patients. JAMA 1987;257:3076-3081

126. Ameda K, Koyanagi $T$, Nantani $M$ et al. The relevance of preoperative cystometrography in patients with benign prostatic hyperplasia: correlating the findings with clinical features and outcome after prostatectomy. J Urol 1994;152:443-447

127. Aboseif SR, Konety B, Schmidt RA et al. Preoperative urodynamic evaluation: does it predict the degree of urinary continence after radical retropubic prostatectomy? Urol Int 1994;53:68-73

128. Kerr LA, Zincke H. Radical retropubic prostatectomy for prostate cancer in the elderly and the young: complications and prognosis. Eur Urol 1994;25:305-311

129. Albertsen PC, Farmington CT, Yao L, Warren J. Risk of complication and readmission associated with radical prostatectomy in community practice: a Medicare claims anlaysis. $J$ Urol 1997;157(Suppl):93

130. Hammerer P, Huland H. Urodynamic evaluation of changes in urinary control after radical retropubic prostatectomy. J Urol 1997; 157:233-236

131. Herzog AR, Fultz NH. Epidemiology of urinary incontinence: prevalence, incidence, and correlates in community populations. Urology 1990;36(Suppl):2-4

132. Fultz NH, Herzog AR. Measuring urinary incontinence in surveys. Gerontologist 1993;33:708-713

133. Barry MJ, Fowler FJ, O'Leary MP et al. Correlation of the American Urological Association symptom index with selfadministered versions of the Madsen-Iversen, Boyarsky and Maine medical assessment program symptom indexes. $J$ Urol 1992;148:1558-1563

134. Bates P, Bradley WE, Glen E et al. The standardization of terminology of lower urinary tract function. $J$ Urol 1979;121:551-554

135. Molander U, Milsom I, Ekelund P, Mellstrom D. An epidemiological study of urinary urinary incontinence and related urogenital symptoms in elderly women. Maturitas $1990 ; 12: 51-60$

136. Kirschner-Hermanns R, Scherr PA, Branch LG et al. Accuracy of survey questions for geriatric urinary incontinence. $J$ Urol 1998; 159:1903-1908

137. Holtedahl K, Hunskaar S. Prevalence, 1-year incidence and factors associated with urinary incontinence: a population based study of women 50-74 years of age in primary care. Maturitas 1998;28:205-211

138. Vetter NJ, Jones DA, Victor CR. Urinary incontinence in the elderly at home. Lancet 1981;ii:1275-1277 
139. O'Brien J, Austin M, Sethi P, O'Boyle P. Urinary incontinence: prevalence, need for treatment, and effectiveness of intervention by nurse. Br Med $J$ 1991;303:1308-1312

140. Cartwright A. Health surveys in practice and in potential: a critical review of their scope and methods. London: King Edward's Hospital Fund, 1983

141. Herzog AR, Fultz NH, Normolle DP et al. Methods used to manage urinary incontinence by older adults in the community. J Am Geriatr Soc 1989;37:339-347

142. Seim A, Sandvik H, Hermstad R, Hunskaar S. Female urinary incontinence - consultation behavior and patient experiences: an epidemiological survey in a Norwegian community. Fam Pract $1995 ; 12: 18-21$

143. Reymert J, Hunskaar S. Why do only a minority of perimenopausal women with urinary incontinence consult a doctor? Scand J Prim Health Care 1994;12:180-183

144. Burgio KL, Ives DG, Locher JL et al. Treatment seeking for urinary incontinence in older adults. $J$ Am Geriatr Soc 1994;42:208-212

145. Seim A, Sivertsen B, Eriksen BC, Hunskaar S. Treatment of urinary incontinence in women in general practice: observational study. Br Med $J$ 1996;312:1459-1462

146. Seim A, Eriksen BC, Hunskaar S. A study of female urinary incontinence in general practice: demography, medical history, and clinical findings. Scand J Urol Nephrol 1996;30:465-471

147. Sandvik H, Hunskaar S. Incontinence pads - prevalence of use and individual consumption. Scand J Soc Med 1993;21:120-121

148. Sandvik H, Kveine E, Hunskaar S. Female urinary incontinence. Psychosocial impact, self care, and consultations. Scand $J$ Caring Sciences 1993;7:53-56

149. Sandvik H, Hunskaar S, Eriksen BC. Management of urinary incontinence in women in general practice: actions taken in the first consultation. Scand J Prim Health Care 1990;8:3-8

150. Andersen JT, Sander P. Minimal care - a new consept for the management of urinary incontinence in an open access, interdisciplinary incontinence clinic. The way ahead? Scand J Urol Nephrol 1996;179(Suppl.):55-60

151. Hunskaar S, Seim A, Freeman T. The journey of incontinent women from community to university clinic; implications for selection bias, gatekeeper function, and primary care. Fam Pract 1996;13:363-368

152. Sandvik H. Female urinary incontinence: studies of epidemiology and management in general practice. Thesis. Bergen: Department of Public Health and Primary Health Care, University of Bergen, Norway, 1995

153. Iosif CS, Bekassy Z. Prevalence of genito-urinary symptoms in the late menopause. Acta Obstet Gynecol Scand 1984;63:257260

154. Milne JS, Williamson J, Maule MM, Wallace ET. Urinary symptoms in older people. Mod Geriatr 1972;2:198-205

155. Ju CC, Swan LK, Merriman A et al. Urinary incontinence among the elderly people of Singapore. Age Aging 1991;20:262 266

156. Shershah S, Ansari RL. The frequency of urinary incontinence in Pakistani women. J Pakistan Med Assoc 1989;39:16-17

157. Lee KS, Chan CJ, Merriman A et al. Clinical profile of elderly urinary incontinence in Singapore: a community based study. Ann Acad Med Singapore 1991;20:736-739

158. Brieger GM, Mongelli M, Hin LY, Chung TKH. The epidemiology of urinary dysfunction in Chinese women. Int Urogynecol J 1997;8:191-195

159. Kato K, Kondo A. Prevalence of urinary incontinence in working women. Jpn J Urol 1986;77:1501-1505

160. Fukui J. Urinary incontinence in women: results of questionnaires. Jpn J Urol 1986;77:707-710

161. Nakanishi N, Tatara K,Naramura $\mathrm{H}$ et al. Urinary and fecal incontinence in a community-residing older population in Japan. J Am Geriatr Soc 1997;45:215-219 